\title{
The Sur1-Trpm4 channel regulates NOS2 transcription in TLR4-activated microglia
}

David B. Kurland ${ }^{1,7^{*}}$, Volodymyr Gerzanich', Jason K. Karimy', Seung Kyoon Woo ${ }^{1}$, Rudi Vennekens ${ }^{4}$, Marc Freichel', Bernd Nilius ${ }^{4}$, Joseph Bryan ${ }^{6}$ and J. Marc Simard ${ }^{1,2,3^{*}}$

\begin{abstract}
Background: Harmful effects of activated microglia are due, in part, to the formation of peroxynitrite radicals, which is attributable to the upregulation of inducible nitric oxide (NO) synthase (NOS2). Because NOS2 expression is determined by $\mathrm{Ca}^{2+}$-sensitive calcineurin (CN) dephosphorylating nuclear factor of activated T cells (NFAT), and because Sur1-Trpm4 channels are crucial for regulating $\mathrm{Ca}^{2+}$ influx, we hypothesized that, in activated microglia, Sur1-Trpm4 channels play a central role in regulating CN/NFAT and downstream target genes such as Nos2.

Methods: We studied microglia in vivo and in primary culture from adult rats, and from wild type, Abcc8- - and Trpm4-/- mice, and immortalized N9 microglia, following activation of Toll-like receptor 4 (TLR4) by lipopolysaccharide (LPS), using in situ hybridization, immunohistochemistry, co-immunoprecipitation, immunoblot, qPCR, patch clamp electrophysiology, calcium imaging, the Griess assay, and chromatin immunoprecipitation.

Results: In microglia in vivo and in vitro, LPS activation of TLR4 led to de novo upregulation of Sur1-Trpm4 channels and CN/NFAT-dependent upregulation of Nos2 mRNA, NOS2 protein, and NO. Pharmacological inhibition of Sur1 (glibenclamide), Trpm4 (9-phenanthrol), or gene silencing of Abcc8 or Trpm4 reduced Nos2 upregulation. Inhibiting Sur1-Trpm4 increased the intracellular calcium concentration $\left(\left[\mathrm{Ca}^{2+}\right]_{\mathrm{i}}\right)$, as expected, but also decreased NFAT nuclear translocation. The increase in $\left[\mathrm{Ca}^{2+}\right]_{i}$ induced by inhibiting or silencing Sur1-Trpm4 resulted in phosphorylation of $\mathrm{Ca}^{2+} / \mathrm{calmodulin}$ protein kinase II and of $\mathrm{CN}$, consistent with reduced nuclear translocation of NFAT. The regulation of NFAT by Sur1-Trpm4 was confirmed using chromatin immunoprecipitation.
\end{abstract}

Conclusions: Sur1-Trpm4 constitutes a novel mechanism by which TLR4-activated microglia regulate pro-inflammatory, $\mathrm{Ca}^{2+}$-sensitive gene expression, including Nos2.

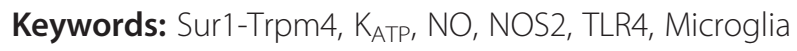

\section{Background}

Toll-like receptor 4 (TLR4)-mediated neuroinflammation figures centrally in a growing list of inflammatory and degenerative conditions of the central nervous system (CNS), including traumatic brain injury, ischemic stroke, hemorrhagic stroke, Alzheimer's disease, multiple sclerosis, Parkinson's disease, and amyotrophic lateral sclerosis [1-4]. These conditions share the common feature that endogenous molecules associated with injury, known as alarmins or danger-associated molecular patterns (DAMPs), converge upon TLR4 and initiate

\footnotetext{
* Correspondence: kurland.davidb@gmail.com; msimard@smail.umaryland.edu 'Department of Neurosurgery, University of Maryland School of Medicine, 22 S. Greene St., Suite S12D, Baltimore, MD 21201-1595, USA

Full list of author information is available at the end of the article
}

potentially deleterious inflammatory cascades $[2,5,6]$. Detrimental effects of chronically activated microglia, which constitutively express TLR4 [7], have been identified in these conditions [8-11]. The ability to inhibit pro-inflammatory actions of microglia following chronic TLR4 activation has the potential to transform the treatment of a variety of degenerative CNS diseases.

A key element in the harmful effects of chronic microglial activation is peroxynitrite-mediated protein radical formation, which is attributable, in part, to de novo upregulation of microglial inducible nitric oxide $(\mathrm{NO})$ synthase (NOS2) [12, 13]. Notably, NOS2 expression in various cell types is dichotomously determined by two factors whose activities are regulated by the concentration of intracellular calcium $\left(\left[\mathrm{Ca}^{2+}\right]_{\mathrm{i}}\right)$ : (i) calcineurin, the 
$\mathrm{Ca}^{2+}$-sensitive phosphatase that, by dephosphorylating nuclear factor of activated T-cells (NFAT), promotes its nuclear translocation to induce Nos2 gene expression $[14,15]$ and (ii) $\mathrm{Ca}^{2+} /$ calmodulin protein kinase II (CaMKII), the $\mathrm{Ca}^{2+}$-sensitive kinase that, by phosphorylating calcineurin, inhibits its phosphatase activity, thereby preventing NFAT nuclear translocation and Nos 2 gene expression $[16,17]$. Thus, mechanisms regulating $\left[\mathrm{Ca}^{2+}\right]_{\mathrm{i}}$ may be crucial for nitrosative injury induced by activated microglia [18-20].

$\mathrm{Ca}^{2+}$ influx via the microglial plasma membrane can occur by multiple mechanisms, including [21] (i) voltageoperated $\mathrm{Ca}^{2+}$ entry (VOCE) channels, which are activated by depolarization of the plasma membrane; (ii) storeoperated $\mathrm{Ca}^{2+}$ entry (SOCE) channels, which are opened upon depletion of intracellular $\mathrm{Ca}^{2+}$ stores; and (iii) receptor-operated $\mathrm{Ca}^{2+}$ entry (ROCE) channels, which are triggered by extracellular ligand binding events. Available data on VOCE channels in microglia are limited [20, 22]. In "electrically non-excitable" cells that do not generate all-or-none action potentials, such as microglia [19, 23], SOCE and ROCE channels serve as the major routes of $\mathrm{Ca}^{2+}$ entry [18-21, 24, 25].

The entry of $\mathrm{Ca}^{2+}$ into a cell is governed by the electrochemical gradient for $\mathrm{Ca}^{2+}$, with the electrical gradient being determined by the cell membrane potential [26]. Sulfonylurea receptor 1 (Sur1)-regulated ion channels have been shown to play critical roles as negative regulators of $\mathrm{Ca}^{2+}$ influx. In cells that utilize VOCE channels, the opening of Sur1-Kir6.2 (ATP-sensitive potassium channel $\left(\mathrm{K}_{\mathrm{ATP}}\right)$ ) channels hyperpolarizes the cell, thereby inactivating VOCE channels and reducing $\mathrm{Ca}^{2+}$ influx [27]. Conversely, in cells that utilize predominantly non-voltage-operated SOCE and ROCE channels, such as microglia [20], the opening of transient receptor potential melastatin 4 (Trpm4) or Sur1-Trpm4 channels depolarizes the cell, thereby reducing the inward driving force for $\mathrm{Ca}^{2+}[26,28-31]$. Notably, Trpm4 and Sur1Trpm4 channels are activated by intracellular $\mathrm{Ca}^{2+}$, with a rise in $\left[\mathrm{Ca}^{2+}\right]_{\mathrm{i}}$ linked directly to membrane depolarization, thereby providing negative feedback to $\mathrm{Ca}^{2+}$ entry through SOCE or ROCE channels [26].

Recent evidence indicates that Sur1 inhibition results in robust anti-inflammatory effects in CNS injury. In models of cerebral ischemia and spinal cord injury, glibenclamide inhibition of Sur1 is associated with enhanced microglial phagocytosis and improved neurological function, with these effects attributed to inhibition of microglial Sur1-Kir6.2 (K $\left.\mathrm{K}_{\text {ATP }}\right)$ channels [32-35]. In models of subarachnoid hemorrhage and multiple sclerosis, gene suppression or pharmacological inhibition (glibenclamide) of $A b c c 8 /$ Sur1 significantly ameliorates neuroinflammation and improves neurological function, with these effects attributed to inhibition of Sur1-Trpm4 channels [36-38]. Importantly, inhibition of $A b c c 8 /$ Sur1 does not distinguish between Sur1-Kir6.2 (K $\left.\mathrm{K}_{\text {ATP }}\right)$ and Sur1-Trpm4 channels.

Here, we hypothesized that microglia activated by TLR4 ligation upregulate Sur1-Trpm4 channels and that, in TLR4-activated microglia, Sur1-Trpm4 channels play a central role in regulating $\left[\mathrm{Ca}^{2+}\right]_{\mathrm{i}}$ and thus the expression of $\mathrm{Ca}^{2+}$-sensitive genes such as Nos2.

\section{Methods \\ Reagents}

Lipopolysaccharide (LPS) [from E. coli R515 (Re), TLRgrade $\left.{ }^{\mathrm{Tx}}\right]$ and FK506 were purchased from Enzo Life Sciences (Farmingdale, NY, USA). Papain, dispase II, glibenclamide, 9-phenanthrol, diazoxide, SKF-96365, A23187, 1,2-bis(2-Aminophenoxy)ethane- $N, N^{\prime}, N^{\prime}, N^{\prime}$-tetraacetic acid acetoxymethyl ester (BAPTA-AM), KN-93, and Percoll were purchased from Sigma-Aldrich (St. Louis, MO, USA). 11R-VIVIT was purchased from EMD Millipore (Billerica, MA, USA). The TLR4 signaling inhibitor, TAK-242, was purchased from Invivogen (San Diego, CA, USA). Artificial cerebrospinal fluid (aCSF) was purchased from Tocris Bioscience (Avonmouth, Bristol, UK). All culture media, sera, antibiotics, DNase I, Fluo-4-AM, and pluronic were obtained from Thermo Fisher Scientific (Waltham, MA, USA). All drugs and Fluo-4-AM were solubilized in dimethylsulfoxide (DMSO) vehicle. Papain, dispase II, and DNase I were solubilized in culture media. Sera and antibiotics were added directly to culture media.

\section{Animals and surgical procedure}

We certify that all applicable institutional and governmental regulations concerning the ethical use of animals were followed during the course of this research. Animal experiments were performed under a protocol approved by the Institutional Animal Care and Use Committee (IACUC) of the University of Maryland, Baltimore and in accordance with the relevant guidelines and regulations as stipulated in the United States National Institutes of Health Guide for the Care and Use of Laboratory Animals. All efforts were made to minimize the number of animals used and their suffering.

Prior to surgery, sterile mini-osmotic pumps (1007D, $0.5 \mu \mathrm{L} / \mathrm{h}$; Alzet, DURECT Corporation, Cupertino, CA, USA) were loaded per the manufacturer's instructions with sterile normal saline (NS; Quality Biological Inc., Gaithersburg, MD, USA) for sham controls, or $0.416 \mathrm{mg} /$ $\mathrm{mL}$ LPS diluted in NS, to deliver $5 \mu \mathrm{g} /$ day LPS. The pumps were attached to sterile brain infusion kits (Alzet; Brain Infusion Kit 2). Male Wistar rats aged 8-12 weeks (Harlan, Indianapolis, IN, USA) were anesthetized $(60 \mathrm{mg} /$ $\mathrm{kg}$ ketamine plus $7.5 \mathrm{mg} / \mathrm{kg}$ xylazine, immunoprecipitation (IP)) and allowed to breathe air spontaneously. Body 
temperature was measured rectally and maintained throughout surgery at $37 \pm 1{ }^{\circ} \mathrm{C}$ using a heating pad (Harvard Apparatus, Holliston, MA, USA). Surgical incision sites were prepared using iodine and alcohol, and a sterile environment was maintained throughout the procedure. Rats were mounted in a stereotactic apparatus (Stoelting Co., Wood Dale, IL, USA). A midline scalp incision was made to expose the skull. A 1-mm burr hole was made over the right striatum $[\mathrm{AP},+0.75 \mathrm{~mm}$; $\mathrm{ML},+1.7 \mathrm{~mm}$ relative to bregma], and the dura was opened sharply. A pre-loaded mini-osmotic pump was attached to a brain infusion kit, and the needle was advanced through the burr hole to a final depth of $5 \mathrm{~mm}$ under stereotaxic guidance. Cyanoacrylate glue was used to secure the applicator to the dorsal surface of the skull.

Wild-type (WT) male C57BL/6J mice were obtained from The Jackson Laboratory (Bar Harbor, ME, USA). Male Abcc8-/- and Trpm4-/- mice were obtained as described previously [39, 40]. Mice were housed under pathogen-free conditions in the animal facility of the University of Maryland School of Medicine. Mice were anesthetized $(60 \mathrm{mg} / \mathrm{kg}$ ketamine plus $7.5 \mathrm{mg} / \mathrm{kg}$ xylazine, IP) and allowed to breathe room air spontaneously. Body temperature was measured rectally and maintained throughout surgery at $37 \pm 1{ }^{\circ} \mathrm{C}$ using a heating pad (Harvard Apparatus, Holliston, MA, USA). All surgical incision sites were prepared with iodine and alcohol, and a sterile environment was maintained during surgical procedures. Mice were mounted in a stereotactic apparatus (Stoelting Co.). A midline scalp incision was made to expose the skull. A 1-mm burr hole was made over the right striatum $(\mathrm{AP},+1 \mathrm{~mm}$; $\mathrm{ML},+1.5 \mathrm{~mm}$; DV, $-2 \mathrm{~mm}$ relative to the bregma), and the dura was opened sharply. A pre-loaded neurosyringe (Stoelting Co.), mounted on the stereotactic frame and containing either sterile aCSF or LPS $(0.1 \mu \mathrm{g} / \mu \mathrm{L})$ in aCSF, was advanced to the final coordinates. Solution $(5 \mu \mathrm{L})$ was infused slowly over $5 \mathrm{~min}$. The syringe was left in place for an additional $5 \mathrm{~min}$ to minimize backflow and then was removed prior to sterile wound closure.

Animals were euthanized by IP injection of pentobarbital (>100 mg/kg), followed by perfusion of NS intracardially. For microglia, RNA, and protein isolation, brains were rapidly harvested and processed using standard techniques, described below. For mice whose brains were to be used for histology, NS perfusion was followed by perfusion with $10 \%$ neutral buffered formalin. The brain was removed, immersion fixed $24 \mathrm{~h}$ in formalin, and cryoprotected $48 \mathrm{~h}$ in $30 \%$ sucrose prior to cryosectioning.

\section{In situ hybridization}

Digoxigenin (DIG)-labeled probes (Integrated DNA Technologies, Coralville, IA, USA) were designed to hybridize to nucleotides located within coding sequences of rat Abcc8, Trpm4, and Kcnj11 genes. The following antisense sequences were used as probes: Abcc8: 5' GCCCGGGCACCCTGCTGGCTCTGTGTGTCCTTC CGCGCCTGGGCATCG-3'; Trpm4: 5'-CCAGGGC AGGCCGCGAATGGAATTCCCGGATGAGGCTGTA GCGCTGCG-3'; and Kcnj11: 5'-GCCACTTGAGGT CCACCAGCGTGGTGAACA-3'. Corresponding sense sequences were used as negative controls. In situ hybridization (ISH) was performed on $10-\mu$ m-thick sections on glass slides using an ISH Kit (Biochain Institute, Inc., Newark, CA, USA) according to the manufacturer's protocol. Sections were washed twice with DEPC-PBS and then were treated with $10 \mu \mathrm{g} / \mathrm{mL}$ proteinase $\mathrm{K}$ at $37^{\circ} \mathrm{C}$ for $10 \mathrm{~min}$. Slides were washed in DEPC-PBS, rinsed with DEPC- $\mathrm{H}_{2} \mathrm{O}$, and pre-hybridized with ready-to-use prehybridization solution (BioChain Institute) for $3 \mathrm{~h}$ at $50{ }^{\circ} \mathrm{C}$. The DIG-labeled probes were diluted in hybridization buffer (BioChain Institute) and applied at $4 \mathrm{ng} / \mu \mathrm{L}$. Sections were incubated at $45^{\circ} \mathrm{C}$ for $16 \mathrm{~h}$. Posthybridization washing and immunological detection, using anti-DIG-HRP and Tyramide Signal Amplification with cyanine 3 (TSA ${ }^{\mathrm{rm}}-\mathrm{Cy} 3$; Perkin Elmer, Waltham, MA, USA), were performed as recommended by the manufacturer. Finally, slides were rinsed in distilled $\mathrm{H}_{2} \mathrm{O}$ and then immunolabeled for P2Y12 using a fluorescent secondary antibody (Alexa Fluor 488), as described below. The red fluorescence indicates $A b c c 8$, Trpm4, or Kcnj11 mRNA; green fluorescence indicates immunohistochemical staining for microglia.

Unbiased measurements of signal intensity within regions of interest (ROIs) were obtained using NISElements AR software (Nikon Instruments, Melville, NY, USA). The area that was evaluated was a square, $1000 \times$ $1000 \mu \mathrm{m}$, centered on the tip of the needle track in the striatum, in the coronal section $200 \mu \mathrm{m}$ rostral to the site of injection. The pixels occupied by specific P2Y12 labeling ( $>2 \times$ background) within this square were defined as the ROI. Specific labeling for Abcc8, Trpm4, or Kcnj11 within the ROI was defined as pixels with signal intensity greater than twice that of the background. Specific ISH labeling within the ROI was normalized to saline-injected control. Results, expressed as fold change in the microglial expression of mRNA, were obtained from five independent experiments.

\section{Immunofluorescence labeling}

Coronal cryosections $(10 \mu \mathrm{m})$ on glass slides were blocked (5\% goat or $2 \%$ donkey serum, $+0.2 \%$ Triton X-100 for $1 \mathrm{~h}$ at room temperature) and then incubated overnight at $4{ }^{\circ} \mathrm{C}$ with primary antibodies. After several rinses in phosphate-buffered saline, the slides were incubated for $1 \mathrm{~h}$ with fluorescent-labeled species-appropriate secondary antibodies (1:500; Alexa Fluor 488 and Alexa Fluor 555; 
Invitrogen, Molecular Probes, Eugene, OR, USA) at room temperature. Omission of primary antibody was used as a negative control. The sections were coverslipped with polar mounting medium containing antifade reagent and 4',6diamidino-2-phenylindole (DAPI; Invitrogen, Eugene, OR, USA) and were examined using epifluorescence microscopy (Nikon Eclipse 90i; Nikon Instruments Inc., Melville, NY, USA). Immunofluorescent labeling of microglial cells cultured on glass chamber slides was carried out similarly, following a 15 -min fixation in $4 \%$ paraformaldehyde.

The following primary antibodies were used: goat antiionized $\mathrm{Ca}^{2+}$-binding adapter molecule 1 (Iba1) $(1: 1,000$; Wako Chemicals, Richmond, VA, USA); rabbit antiP2Y12 (1:200; Anaspec, Fremont, CA, USA); mouse anti-ED1 (1:500; EMD Millipore); rabbit anti-Sur1 (1:200, custom [41]); rabbit anti-Trpm4 (1:200, custom [41]); goat anti-Kir6.2 (1:200, G-16, Santa Cruz); and mouse anti-NFATc1 (1:200, Santa Cruz).

For quantitative immunohistochemistry, all tissue and cells were immunolabeled as a single batch, and all images were collected using uniform parameters of magnification and exposure, as previously described [37]. Unbiased measurements of signal intensity within ROIs were obtained using NIS-Elements AR software (Nikon Instruments). Segmentation analysis was performed by computing a histogram of pixel intensity for a particular ROI. Quantification of microglial expression of Sur1, Trpm4, and Kir6.2 in vivo was performed as described above for ISH, using P2Y12 immunolabeling as the ROI.

For quantification of nuclear translocation of NFATc1 in vitro, the nuclei of 50 cells or more were analyzed, with the ROI defined by DAPI labeling. Specific labeling for NFATc1 within the ROI was defined as pixels with signal intensity greater than twice that of the background. Specific labeling within the ROI was normalized to DAPI. Results were obtained from five independent experiments.

\section{Isolation and culture of primary adult microglia}

A highly enriched population of microglia was isolated by Percoll density centrifugation from adult rat brains and adult WT, $A b c c 8-/-$, and Trpm4-/- mouse brains using a protocol described previously [42]. Briefly, an adult rat or mouse was perfused with ice-cold saline and the intact brain was collected and placed onto a $35-\mathrm{mm}$ dish in 2-mL ice-cold serum free cell culture medium. The brain was finely minced with a razor blade, transferred to a $15-\mathrm{mL}$ tube containing $3 \mathrm{~mL}$ of dissociation medium [papain $(1 \mathrm{mg} / \mathrm{mL})$, dispase II $(1.2 \mathrm{U} / \mathrm{mL})$, and DNase I $(20 \mathrm{U} / \mathrm{mL})$ in serum free medium] and incubated at $37^{\circ} \mathrm{C}$ with constant agitation for $30 \mathrm{~min}$. The enzymes were neutralized by adding $5 \mathrm{~mL}$ of culture medium containing serum, and debris was removed by 5 -min centrifugation at $250 \times g$, followed by a resuspension of the pellet in serum-free medium. Following gentle trituration, the cell suspension was filtered sequentially through 100-, 70-, and $40-\mu \mathrm{m}$ mesh cell strainers (Thermo Fisher Scientific). Debris was removed by 5 -min centrifugation at $250 \times g$, and the pellet was resuspended in $4 \mathrm{~mL} 37 \%$ standard isotonic Percoll (SIP). Homogenized brain tissue suspended in $37 \%$ SIP was transferred to a new $15-\mathrm{mL}$ tube, underlaid with $4 \mathrm{~mL} 70 \%$ SIP and overlaid with $4 \mathrm{~mL} 30 \%$ SIP following by $2 \mathrm{~mL}$ of Hank's balanced salt solution (HBSS). Following centrifugation at $300 \times g$ for $40 \mathrm{~min}$ at $18{ }^{\circ} \mathrm{C}$, a distinct interphase layer containing microglia could be observed. This layer was carefully removed and washed by centrifugation twice, as described above.

The purity of isolated cells was determined by quantitative real-time polymerase chain reaction (qPCR). Microglia from one rat were suspended in Dulbecco's modified Eagle's medium (DMEM)/F12 plus $10 \%$ fetal bovine serum (FBS) to a concentration of $5 \times 10^{5}$ cells/ $\mathrm{mL}$ and plated onto 6-well culture dishes (Corning). Microglia from one mouse were suspended in DMEM/ F12 plus $10 \%$ FBS to a concentration of $5 \times 10^{5}$ cells/ $\mathrm{mL}$ and plated onto two wells of a 96-well plate (Corning) to allow for paired analysis of control versus LPS treatment conditions from one animal. All experiments with primary microglia were begun following an overnight incubation at $37^{\circ} \mathrm{C}$ with $5 \% \mathrm{CO}_{2}$.

\section{RNA isolation and quantitative real-time polymerase chain reaction}

The MIQE guidelines [43] were consulted for the preparation, handling, and analysis of qPCR samples. Microglial cells were homogenized in Trizol Reagent (Thermo Fisher Scientific), and total RNA was isolated with Direct-zol $^{\text {Tw }}$ RNA MiniPrep Kit (Zymo Research; Irvine, CA, USA). To avoid contamination by genomic DNA, RNA was further purified with Amplification Grade DNase I (Invitrogen). The concentration of total RNA was determined by measuring the optical density at 260 and $280 \mathrm{~nm}$. The quality of RNA was evaluated using an Agilent Bioanalyzer (Agilent Technologies; Santa Clara, CA, USA); samples with an RNA integrity number (RIN) $<7$ were excluded from analysis.

cDNA was synthesized from $1 \mu \mathrm{g}$ of total RNA of each sample using SuperScript III Reverse Transcriptase (RT) Supermix (Thermo Fisher Scientific). Generated cDNAs were stored at $-20{ }^{\circ} \mathrm{C}$. qPCR reactions $(25 \mu \mathrm{L})$, consisted of $1 \mu \mathrm{L}$ cDNA template, Platinum SYBR Green SuperMixUDG with ROX ( $2 \times$ concentrated, Thermo Fisher Scientific), specific primers, and ultra-pure $\mathrm{H}_{2} \mathrm{O}$. The abundance of various mRNA in the samples was determined by qPCR (ABI PRISM 7300; Applied Biosystems, Carlsbad, CA, USA). Reactions were incubated at $50{ }^{\circ} \mathrm{C}$ for $2 \mathrm{~min}$ and $95{ }^{\circ} \mathrm{C}$ for $2 \mathrm{~min}$, followed by 40 cycles of $95{ }^{\circ} \mathrm{C}$ for $15 \mathrm{~s}$ and $60{ }^{\circ} \mathrm{C}$ for $30 \mathrm{~s}$, followed by melting 
curve analysis. No-template and no-RT reactions were used as negative controls in every experiment. The absence of PCR inhibitors in the reactions was determined using the Alien Reference RNA qPCR Detection Kit (Agilent Technologies). Rps18 and glyceraldehyde 3-phosphate dehydrogenase (Gapdh) mRNA were measured as reference genes to normalize the samples. The primers used in this study are listed in Table 1. Melting curve analysis was used to confirm the validity of experimental results.

\section{Patch clamp electrophysiology}

Patch clamp electrophysiology was performed as described $[41,44,45]$. Whole cell recordings were performed using a nystatin perforated patch technique, to minimize the disturbance of the intracellular mileu that causes rapid rundown of Trpm4 currents [46, 47]. Nystatin, $50 \mathrm{mg}$, (Calbiochem, San Diego, CA, USA) was dissolved in DMSO, $1 \mathrm{ml}$. Working solutions were made before the experiment by adding $16.5 \mu \mathrm{L}$ nystatin stock solution to $5 \mathrm{~mL}$ of the base pipette solution to yield a final concentration of nystatin of $165 \mu \mathrm{g} / \mathrm{mL}$ and DMSO $3.3 \mu \mathrm{L} / \mathrm{ml}$.

To record whole cell macroscopic currents under "physiological" conditions, the extracellular solution contained $(\mathrm{mM}) \mathrm{NaCl} 130, \mathrm{KCl} 10, \mathrm{CaCl}_{2} 1, \mathrm{MgCl}_{2} 1$, HEPES 32.5, glucose 12.5, and $\mathrm{pH} 7.4$ and the pipette solution contained (mM) KCl $55, \mathrm{~K}_{2} \mathrm{SO}_{4} 75, \mathrm{MgCl}_{2} 8$, and HEPES 10, and nystatin, $165 \mu \mathrm{g} / \mathrm{mL}, \mathrm{pH} 7.2$.

To record whole cell macroscopic currents exclusive of $\mathrm{K}^{+}$channels, the extracellular solution contained (mM) CsCl 145, $\mathrm{CaCl}_{2} 1, \mathrm{MgCl}_{2}$ 1, HEPES 32.5, glucose 12.5 , and $\mathrm{pH} 7.4$ and the pipette solution contained (mM) $\mathrm{CsCl} 145, \mathrm{MgCl}_{2}$ 8, and HEPES 10 , and nystatin, $165 \mu \mathrm{g} / \mathrm{mL}, \mathrm{pH}$ 7.2.

The following parameters were used: holding potential, $-50 \mathrm{mV}$; ramp pulses were from -100 to $+100 \mathrm{mV}$, $4 \mathrm{mV} / \mathrm{msec}$, applied every $15 \mathrm{~s}$.

Steady-state inward currents were quantified at $-50 \mathrm{mV}$ and are presented in bar graphs as positive values, normalized to cell capacitance.

\section{Cell culture}

The N9 murine microglial cell line (Neuro-Zone, Milan, Italy) was cultured in Iscove's modified Dulbecco's medium (IMDM) with $5 \%$ FBS. N9 cells were seeded at $1.5 \times 10^{5}$ cells $/ \mathrm{mL}$ and allowed to adhere overnight prior to experimental manipulation. LPS was used at a final concentration of $1 \mu \mathrm{g} / \mathrm{mL}$ to activate TLR4; all experiments with LPS were performed in $5 \%$ FBS. Glibenclamide $(30 \mu \mathrm{M})$, diazoxide $(100 \mu \mathrm{M})$, 9-phenanthrol $(5 \mu \mathrm{M})$, A23187 $(1 \mu \mathrm{M})$, BAPTA-AM $(10 \mu \mathrm{M})$, SKF$96395(7.5 \mu \mathrm{M})$, TAK-242 $(3 \mu \mathrm{M})$, FK506 $(1 \mu \mathrm{M})$, and 11R-VIVIT $(10 \mu \mathrm{M}), \mathrm{KN}-93(3 \mu \mathrm{M})$, all dissolved in DMSO, were used at final concentrations indicated, and were added concurrently with LPS for immunofluorescence and immunoblot experiments. Reagents were added at the time of recording for $\mathrm{Ca}^{2+}$ imaging experiments. Cultured cells were maintained $37{ }^{\circ} \mathrm{C}$ and $5 \%$ $\mathrm{CO}_{2}$.

All cell culture experiments were carried out in the presence of $5 \%$ FBS. Glibenclamide is reported to be $99 \%$ protein bound [48], indicating that the free concentration of drug would be much less than that the apparent concentration that was added. We independently verified the reported degree of protein binding using a method that we previously described for measuring free drug concentration [49]. Briefly, various amounts of a stock solution of glibenclamide $(25 \mathrm{mg}$ per $\mathrm{mL}$ of DMSO) were added to NS containing $5 \% \mathrm{FBS}$, and the solution was dialyzed against NS (Mini Slide-A-Lyzer, 3.5 K MWCO; Thermo Fisher Scientific). The concentration of glibenclamide in the dialysate was measured spectrophotometrically (absorbance at $239 \mathrm{~nm}$ ), and the final concentration was determined using a standard curve that we constructed. For each concentration, dialysis reactions with vehicle were performed to control for the background. Linear fit of data at different concentrations of glibenclamide showed that drug was $98.8 \%$ protein bound.

\section{Immunoprecipitation and immunoblotting}

For immunoprecipitation experiments, total lysate from N9 cells was prepared in 3-[(3-cholamidopropyl)dimethylammonio]-1-propanesulfonate (CHAPS) lysis buffer (pH 8.0; FivePhoton Biochemicals, San Diego, CA, USA) supplemented with freshly added protease and phosphatase inhibitor cocktail (PPI, Cell Signaling Technology, Danvers, MA, USA) and spermidine (100 mM, Sigma-Aldrich). Crude lysate was homogenized by centrifugation through a Qiashredder column (2 minutes; 6,000 RPM; QIAGEN, Valencia, CA, USA), and the pellet was gently resuspended to minimize loss of hydrophobic membrane proteins. Prior to lysate collection for co-immunoprecipitation experiments, protein crosslinking was performed in cell culture dishes using $1 \mathrm{mM}$ DSP (dithiobis(succinimidyl propionate); Thermo Fisher Scientific) according to the manufacturer's instructions.

We followed our previously validated approach to evaluate the expression of Sur1 and Trpm4 by immunoblot [41]. To immunoprecipitate Sur1 or crosslink-stabilized Sur1-Trpm4, a custom goat anti-Sur1 antibody [41] was incubated with Dynabeads Protein G (Thermo Fisher Scientific) according to the manufacturer's instructions. To immunoprecipate Trpm4, a custom chicken antiTrpm4 antibody [41] was covalently coupled to Dynabeads M-270 Epoxy according to the manufacturer's instructions using an antibody coupling kit (Thermo Fisher Scientific). Following a wash step, crude lysate was 
Table 1 Primers used for GPCR in this study

\begin{tabular}{|c|c|c|c|c|}
\hline Gene name & Species & Sequence accession number & Primer sequence & Amplicon length \\
\hline \multirow[t]{2}{*}{$\overline{A b c c 8}$} & Rat & NM_013039.2 & 5'-TCATCCGGGTGAGGAGATAC-3' (+) $^{\prime}$ & 130 \\
\hline & & & 5'-CACCAGTAGGTCCCCTTTGA-3' (-) & \\
\hline \multirow[t]{2}{*}{ Trpm4 } & Rat & NM_001136229.1 & 5'-GCAAGTTCTGAGGACTCTGTTG-3' (+) & 140 \\
\hline & & & 5'-TTGCATCCTGTTGCATGTTGGC-3' (-) & \\
\hline \multirow[t]{2}{*}{ Kenj11 } & Rat & NM_031358.3 & 5'-TGCGTCACAAGCATCCACTCCT-3' (+) & $100^{\mathrm{a}}$ \\
\hline & & & 5'-GGACATTCCTCTGTCACCATGC-3' (-) & \\
\hline \multirow[t]{2}{*}{ Kcnj8 } & Rat & NM_017099.4 & 5'-CACTTCGGGAGGTCTCTGC-3' (+) & 69 \\
\hline & & & 5'-GCGTCCTCCTAGAAGACTCGG-3' (-) & \\
\hline \multirow[t]{2}{*}{$11-1 \beta$} & Rat & NM_031512.2 & 5'-AAATGCCTCGTGCTGTCTGA-3' (+) & 85 \\
\hline & & & 5'-TGGAGAATACCACTTGTTGGC-3' (-) & \\
\hline \multirow[t]{2}{*}{ P2y 12} & Rat & NM_022800.1 & $5^{\prime}$-CTTTGGCAACGAAACCAAGT-3' (+) & 127 \\
\hline & & & 5'-CACCTCCATGGTCCTGGTTA-3' (-) & \\
\hline \multirow[t]{2}{*}{ T/r4 } & Rat & NM_019178.1 & 5'-TCATGCTITCTCACGGCCTC-3' (+) & 142 \\
\hline & & & 5'-AGGAAGTACCTCTATGCAGGGAT-3' (-) & \\
\hline \multirow[t]{2}{*}{ Gfap } & Rat & NM_017009.2 & $5^{\prime}$-CCAGATCCGAGAAACCAGCC-3' (+) & 88 \\
\hline & & & 5'-CCGCATCTCCACCGTCTTTA-3' (-) & \\
\hline \multirow[t]{2}{*}{ Neun } & Rat & NM_001134498.2 & 5'-CGCAGCCTACAGTGACAGTTAT-3' (+) & 132 \\
\hline & & & 5'-GTGAAGCGGCTGTACCCTC-3' (-) & \\
\hline \multirow[t]{2}{*}{ Gapdh } & Rat & NM_017008.4 & $5^{\prime}$-CATCACTGCCACTCAGAAGACTG-3' (+) & $153^{b}$ \\
\hline & & & 5'-ATGCCAGTGAGCTTCCCGTTCAG-3' (-) & \\
\hline \multirow[t]{2}{*}{$A b c c 8$} & Mouse & NM_011510.3 & 5'-GCCAGCTCTITGAGCATTGG-3' (+) & 102 \\
\hline & & & 5'-AGGCCCTGAGACGGTTCTG-3' (-) & \\
\hline \multirow[t]{2}{*}{ Trpm4 } & Mouse & NM_175130.4 & 5'-TGTTGCTCAACCTGCTCATC-3' (+) & 83 \\
\hline & & & 5'-GCTGTGCCTTCCAGTAGAGG-3' (-) & \\
\hline \multirow[t]{2}{*}{ Kcnj11 } & Mouse & NM_010602.3 & 5'-TGCGTCACAAGCATCCACTCCT-3' (+) & $100^{c}$ \\
\hline & & & 5'-GGACATTCCTCTGTCACCATGC-3' (-) & \\
\hline \multirow[t]{2}{*}{$11-6$} & Mouse & NM_031168.2 & 5'-CCCCAATTTCCAATGCTCTCC-3' (+) & 141 \\
\hline & & & 5'-CGCACTAGGTTTGCCGAGTA-3' (-) & \\
\hline \multirow[t]{2}{*}{ Nos2 } & Mouse & NM_010927.4 & 5'-TGGAGCGAGTTGTGGATTGTC-3' (+) & 98 \\
\hline & & & 5'-GGGCAGCCTCTTGTCTTTGA-3' (-) & \\
\hline \multirow[t]{2}{*}{ Fth1 } & Mouse & NM_010239.2 & 5'-CGAGATGATGTGGCTCTGAA-3' (+) & 94 \\
\hline & & & 5'-TCTGCAGCTTCATCAGTTTCTC-3' (-) & \\
\hline \multirow[t]{2}{*}{$C d 11 b$} & Mouse & NM_001082960.1 & 5'-AAGGATTCAGCAAGCCAGAA-3' (+) & 100 \\
\hline & & & 5'-TACTCTTCAGAGCCCCATGC-3' (-) & \\
\hline \multirow[t]{2}{*}{ Gfap } & Mouse & NM_001131020.1 & $5^{\prime}$-TGCTGGAGGGCGAAGAAAACCG-3' (+) & 83 \\
\hline & & & 5'-TTTGGTGCTTTGGCCCCCTCGG-3' (-) & \\
\hline \multirow[t]{2}{*}{ Neun } & Mouse & NM_001039167.1 & $5^{\prime}-$ GTTGCCTACCGGGGTGCACAC-3' (+) & 110 \\
\hline & & & 5'-TGCTCCAGTGCCGCTCCATAAG-3' (-) & \\
\hline \multirow[t]{2}{*}{ Rps18 } & Mouse & NM_011296.2 & 5'-CGGAAAATAGCCTTCGCCATCAC-3' (+) & 134 \\
\hline & & & 5'-ATCACTCGCTCCACCTCATCCT-3' (-) & \\
\hline \multirow[t]{2}{*}{ Gapdh } & Mouse & NM_008084.3 & 5'-CATCACTGCCACCCAGAAGACTG-3' (+) & $153^{d}$ \\
\hline & & & 5'-ATGCCAGTGAGCTTCCCGTTCAG-3' (-) & \\
\hline
\end{tabular}

For Kcnj11 and Gapdh, same primers used for rat and mouse

${ }^{a}$ Amplicon is from 564 to 664

${ }^{\mathrm{b}}$ Amplicon is from 609 to 761

c Amplicon is from 668 to 768

d Amplicon is from 584 to 736 
added to the antibody-bound magnetic beads and incubated with constant rotation overnight at $4{ }^{\circ} \mathrm{C}$. The immune complexes formed were isolated by placing the reaction tube against a magnet and washed twice with lysis buffer. To elute the proteins and fully reduce crosslinked proteins, the beads were resuspended in a $2 \times$ LDS sample buffer with $1 \times$ reducing agent (Thermo Fisher Scientific), vortexed at full speed and then kept at $37{ }^{\circ} \mathrm{C}$ for $30 \mathrm{~min}$. Following application of a strong magnet to remove the beads, the resulting samples were used directly for sodium dodecyl sulfate polyacrylamide gel electrophoresis (SDS-PAGE) and were examined by immunoblot analysis. Reactions using plain beads (lysate without addition of IP antibody) and antibody only (beads and IP antibody without the addition of lysate) were used as negative controls. In order to study individual protein expression, we performed immunoprecipitation of Sur1 followed by immunoblot of Sur1, or immunoprecipitation of Trpm4 followed by immunoblot of Trpm4. In order to study the interaction between Sur1 and Trpm4, we performed immunoprecipitation of Sur1 followed by immunoblot of Trpm4. Sur1 or Trpm4 proteins were detected using custom rabbit anti-Sur1 and rabbit anti-Trpm4 antibodies [41].

For the analysis of the subcellular localization of proteins in N9 microglia, an optimized protocol for the fractionation of cytoplasmic versus nuclear protein was performed rapidly, as follows. First, adhered cells were incubated in ice-cold hypotonic buffer containing dilute detergent $(10 \mathrm{mM}$ Tris, $0.1 \%$ Triton X-100, supplemented with PPI) for $3 \mathrm{~min}$. With the aid of a cell scraper, cells were collected into a $1.5-\mathrm{mL}$ tube and vortexed for $3 \mathrm{~s}$. The contents were immediately centrifuged for $5 \mathrm{~min}$, and the supernatant containing soluble cytoplasmic proteins was collected in a new tube. The remaining pellet containing intact nuclei was then resuspended in radio-immunoprecipitation assay (RIPA) lysis buffer (Thermo Fisher Scientific) supplemented with PPI and left on ice for $10 \mathrm{~min}$ to allow for dissolution of nuclear membranes. Following this, a reduction in the viscosity of nuclear protein samples was carried out by homogenization through a Qiashredder column, as above. Successful fractionation was confirmed via immunoblot of the cytoplasmic protein lactate dehydrogenase $(\mathrm{LDH})$ and the nuclear protein histone deacetylase 1 (HDAC1). For all other applications, unless otherwise stated, protein was harvested in RIPA lysis buffer supplemented with PPI and homogenized by centrifugation through a Qiashredder column.

The following primary antibodies were used: mouse anti-NFATc1 (1:200; 7A6, Santa Cruz); rabbit antiphosphorylated CaMKII (Thr286, pCaMKII, 1:2,000, Cell Signaling Technology); rabbit anti-CaMKII (pan, 1:2,000, Cell Signaling Technology); mouse anti-NOS2 (1:2,000,
Thermo Fisher Scientific); rat anti-HSC70 (1:10,000, Abcam, Cambridge, MA, USA); rabbit anti-phosphorylated calcineurin (Ser197, pCN, 1:200; Badrilla Ltd., Leeds, UK); rabbit anti-calcineurin (pan, 1:1000; Cell Signaling Technology); rabbit anti-LDH (1:2,000, Santa Cruz); and mouse anti-HDAC1 (1:10,000, Cell Signaling Technology). Protein was detected using species-appropriate horse radish protein-tagged secondary antibodies (Cell Signaling Technology). Detection was performed using the ECL system (Amersham BioSciences Inc., Piscataway, NJ, USA) with routine imaging (Fuji LAS-3000) and quantification (ImageJ). For NFATc1, band densities of each isoform (1-3) were combined into a single value for quantification, which was done similarly for the two major isoforms of CaMKII $(\alpha / \beta)$. Acquired data were normalized to appropriate loading controls.

\section{$\mathrm{Ca}^{2+}$ imaging}

Changes in intracellular $\mathrm{Ca}^{2+}$ were assessed in N9 microglia using a $\mathrm{Ca}^{2+}$-sensitive indicator, Fluo-4-AM (Invitrogen), as previously reported [50]. Cells were cultured on 35-mm fluorodishes (World Precision Instruments; Sarasota, FL, USA). Prior to $\mathrm{Ca}^{2+}$ imaging experiments, the cells were incubated overnight in phenol red-free and serum-free culture medium. A stock solution containing Fluo-4-AM and the non-toxic dispersing agent, Pluronic F-127, was then added directly to the cells to final concentrations of $5 \mu \mathrm{M}$ and $0.02 \%$, respectively. Loading of $\mathrm{Ca}^{2+}$ indicator was performed for $30 \mathrm{~min}$ at $37^{\circ} \mathrm{C}$. After loading, cells were gently washed with and then maintained in phenol red-free and serum-free culture medium. For imaging, loaded cells were placed in a temperature controlled chamber $\left(37^{\circ} \mathrm{C}\right)$ on the stage of a confocal microscope (LSM Duo, Zeiss, Germany) and allowed to equilibrate for $15 \mathrm{~min}$. For each experiment, complete equilibration was confirmed by imaging for a short time series ( $3 \mathrm{~min})$ and observing a plateau of fluorescence signal. Using a $20 \times$ objective, Fluo-4-AM-loaded cells were excited by a HeNe Laser source with a $488 \pm 10-\mathrm{nm}$ excitation, and the fluorescence signal was collected at $530 \pm 10$-nm emission. For each experiment, images were taken every $4 \mathrm{~s}$ and the field was recorded for 10 mins. From each field, ten cells were chosen randomly for analysis. The changes in the fluorescence intensity within the selected cells were quantitatively analyzed using Zen software (Zeiss). Results were obtained from a minimum of three independent experiments.

\section{Chromatin immunoprecipitation}

Chromatin immunoprecipitation (ChIP) was performed to study NFATc1 binding to the Nos2 promoter using ChIP-IT $^{\bullet}$ High Sensitivity kit (Active Motif; Carlsbad, CA, USA). Chromatin was prepared as follows, from N9 microglia. Cells were fixed, lysed, and then sonicated to 
fragment chromatin, according to the manufacturer's instructions. After validating chromatin shearing efficiency via gel electrophoresis, immunoprecipitation of NFATc1DNA complexes was performed using ChIP-validated rabbit anti-NFATc1 antibody (H-110, Santa Cruz Biotechnology). For each reaction, $4 \mu \mathrm{g}$ DNA and $0.4 \mu \mathrm{g}$ antibody were used, and the reactions were incubated overnight at $4{ }^{\circ} \mathrm{C}$ under constant rotation. Parallel immunoprecipitation reactions using equivalent amounts of rabbit IgG were performed as background controls. Following reversal of crosslinks and purification of DNA, qPCR was performed as described above using primers aligned with an NFAT binding site (-1000 to -877$)$ on the Nos2 promoter [14]. We analyzed the Nos 2 promoter using MatInspector software (Genomatix Inc.; Ann Arbor, MI, USA) and independently identified this NFAT binding site.

\section{MTT assay}

Cell viability was measured using the Vybrant ${ }^{\circ}$ MTT Cell Proliferation Assay Kit (Thermo Fisher Scientific). Briefly, a 12-mM MTT stock solution was prepared by adding $1 \mathrm{~mL}$ of sterile PBS to one 5-mg vial of MTT; $10 \mu \mathrm{L}$ of the 12-mM MTT stock solution was added to cells cultured in 96-well plates containing $100 \mu \mathrm{L}$ media and incubated at $37{ }^{\circ} \mathrm{C}$ for $4 \mathrm{~h}$. After labeling the cells with MTT, all but $25 \mu \mathrm{L}$ of medium was removed from the wells; $50 \mu \mathrm{L}$ of DMSO was added to each well and mixed thoroughly, followed by an incubation at $37{ }^{\circ} \mathrm{C}$ for $10 \mathrm{~min}$. Absorbance was read at $540 \mathrm{~nm}$; a decrease in absorbance in treatment groups versus control indicated reduced cell viability.

\section{Griess assay}

Nitrite was quantified from N9 microglia culture media using a Griess Reagent Kit (Thermo Fisher Scientific), according to the manufacturer's instructions. Briefly, equal volumes of $\mathrm{N}$-(1-naphthyl)ethylenediamine (component A) and sulfanilic acid (component B) were combined to form the Griess Reagent; $20 \mu \mathrm{L}$ of the Griess Reagent was added to $150 \mu \mathrm{L}$ of the nitrite containing sample, followed by the addition of $130 \mu \mathrm{L}$ deionized water. Following a 30-min incubation at room temperature, the absorbance was measured at $548 \mathrm{~nm}$. Calibrations and standard curves were generated from sodium nitrite standards $(1-100 \mu \mathrm{M})$.

\section{Statistical analysis}

Data are presented as mean \pm standard error. Statistical comparisons were made using Student's $t$ test or analysis of variance (ANOVA), as appropriate, with post hoc comparisons made using Fisher's method. Calculations were performed with OriginPro2016 (OriginLab Corp., Northampton, MA, USA). A value $p<0.05$ was considered to be statistically significant.

\section{Results}

Sur1-Trpm4 upregulation in TLR4-activated microglia TLR4 activation in vivo induces Sur1-Trpm4 channel expression in microglia

LPS infusion into the striatum of adult rats, which leads to nitrosative/oxidative stress and neuroinflammation [51], was used as a model to study TLR4 activation in vivo. Microglia were identified using various markers, including the purinergic receptor, P2Y12, which is expressed by microglia but not by infiltrating myeloid cells, and Iba1, cluster of differentiation molecule 11b (Cd11b), and cluster of differentiation molecule 68 (CD68/ED1), with the last three expressed by both microglia and myeloid cells [52]. Following TLR4 activation for $6 \mathrm{~h}$ in vivo, $\mathrm{Iba1}^{+}$cells were localized both within the CNS parenchyma and in the subarachnoid space, consistent with both resident microglia and infiltrating monocytes (Fig. 1a, upper panels), whereas $\mathrm{P} 2 \mathrm{Y}_{12}{ }^{+}$cells were identified only in the CNS parenchyma, consistent with selective expression by microglia (Fig. 1a, lower panels). In subsequent experiments, P2Y12 immunolabeling was employed to identify microglia distinct from infiltrating myeloid cells.

TLR4 activation in vivo for $24 \mathrm{~h}$ led to the development of an activated microglial phenotype [53]. Activation was characterized by a morphological shift from a highly ramified appearance in quiescent, P2Y12 $2^{+}$microglia, which were $\mathrm{ED} 1^{-}$, to an amoeboid appearance in TLR4-activated $\mathrm{P} \mathrm{Y}_{12}{ }^{+}$microglia, which were ED1 ${ }^{+}$(Fig. 1b, c).

Microglial expression of mRNA for Abcc8, Trpm4, and Kcnj11, the genes that express Sur1, Trpm4, and Kir6.2, was evaluated in vivo using combined in situ hybridization and immunofluorescence protein labeling in the same tissue section [54, 55], with P2Y12 immunolabeling used as the specific microglial marker. TLR4-activated P2Y12 ${ }^{+}$ cells upregulated transcripts for $A b c c 8$ and Trpm4 (fold increase of $6.33 \pm 0.88$ and $3.14 \pm 0.37$, respectively, $p<$ 0.01; Fig. 2a, b); no change in expression of Kcnj11 transcripts was observed (Fig. 2c).

Immunolabeling for Sur1, Trpm4, and Kir6.2 protein was evaluated in P2Y12 ${ }^{+}$cells following TLR4 activation (Fig. 3). TLR4-activated P2Y12 ${ }^{+}$cells exhibited enhanced immunolabeling for Sur1 and Trpm4 (fold increase of $3.05 \pm 0.57$ and $4.11 \pm 0.78$, respectively, $p<0.01$; Fig. 3a, b). Consistent with a lack of Kcnj11 induction, TLR4-activated P2Y12 cells exhibited no change in Kir6.2 immunolabeling (Fig. 3c). Taken together, these data indicated that microglial activation by TLR4 in vivo resulted in the upregulation of mRNA and protein for the two subunits of the Sur1-Trpm4 channel, but not the pore-forming subunit of $\mathrm{K}_{\mathrm{ATP}}$.

\section{TLR4 activation induces Sur1-Trpm4 channel expression in primary cultured adult microglia}

We used primary cultured adult rat microglia to determine if the induction of $A b c c 8 /$ Sur1 and Trpm4/Trpm4 


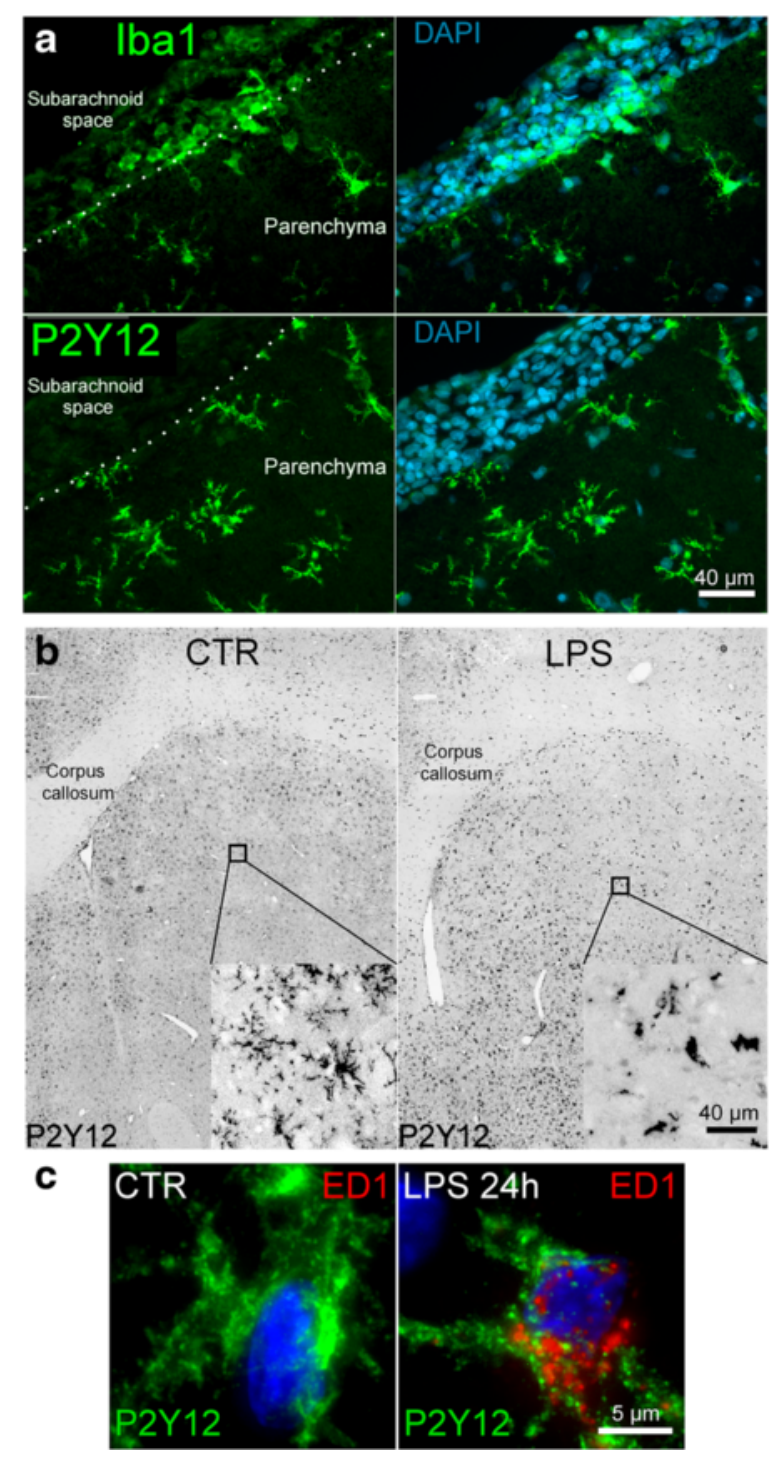

Fig. 1 Model of TLR4 activation of rat microglia in vivo. a Immunofluorescence images of adjacent 10- $\mu$ m coronal brain sections $6 \mathrm{~h}$ after intrastriatal infusion of LPS (rate, $5 \mu \mathrm{g} /$ day); $\mathrm{Iba}^{+}$ cells (green, upper) versus P2Y12+ cells (green, lower); dotted line demarcates the pial layer separating the subarachnoid space from the parenchyma; nuclei labeled with DAPI (blue); scale bar $40 \mu \mathrm{m}$. b Grayscale images of brain sections of control (CTR) versus $24 \mathrm{~h}$ after intrastriatal infusion of LPS (LPS 24 h); cc corpus callosum; P2Y12 labeling (black); morphological changes in activated microglia are shown in the inset; scale bar $40 \mu \mathrm{m}$. c High magnification immunofluorescence images representative of microglia under control (CTR) conditions versus $24 \mathrm{~h}$ after intrastriatal infusion of LPS (LPS 24 h); P2Y12 (green) and ED1 (red); nuclei labeled with DAPI (blue)

that we observed in vivo following TLR4 ligation was associated with the formation of functional Sur1-Trpm4 channels. Isolated cells were highly enriched for microglia $\left(\right.$ P2y $12 r^{+} /$Tlrt $^{+}$and Gfap /Neun $\left.^{-}\right)$and reacted similarly to quiescent microglia in vivo, responding to TLR4 ligation with a shift in morphology from ramified to amoeboid (Fig. 4a).

Following TLR4 ligation, Abcc 8 mRNA was significantly upregulated at 6 and $24 \mathrm{~h}$ (5.6- and 2.2-fold vs. control, respectively, $p<0.05)$, as was mRNA for Trpm4 (1.4- and 1.9-fold vs. control, respectively, $p<0.05$ ) (Fig. $4 \mathrm{~b}$ ), corroborating our observations in vivo. mRNA for $I l-1 \beta$ also was significantly upregulated at both times (11.6- and 10.3-fold vs. control, respectively, $p<0.05$ ). No change was observed in Kcnj11 mRNA at either time. Consistent with the induction of $A b c c 8$ and Trpm4, enhanced immunolabelings for Sur1 and Trpm4 were observed $24 \mathrm{~h}$ after TLR4 activation, but no change in Kir6.2 immunoreactivity was apparent (Fig. 4c).

Sur1 forms heteromers not only with Kir6.2 (Kcnj11), but also with Kir6.1 (Kcnj8) [56, 57]. Following TLR4 ligation for $24 \mathrm{~h}$, Kcnj8 expression was decreased significantly (5.2-fold vs. control, $p<0.01$; data not shown), suggesting that $K_{\text {ATP }}$ comprised of Sur1-Kir6.1 is unlikely to play a role in TLR4-activated microglia.

Patch clamp recordings showed that quiescent primary rat microglia exhibited currents attributable to Sur1Kir6.2 ( $\left.\mathrm{K}_{\mathrm{ATP}}\right)$ channels. Under basal conditions, currents recorded in physiological solutions (principal charge carriers, $\mathrm{K}^{+}$intracellularly and $\mathrm{Na}^{+}$extracellularly) showed both inward and delayed outward rectifier $\mathrm{K}^{+}$currents that reversed at $-75 \mathrm{mV}$, typical of primary microglia [58] (Fig. 4d, CTR). We used diazoxide to activate Sur1regulated channels. Diazoxide activated a current that reversed at $-75 \mathrm{mV}$, showed minimal conductance between the $E_{\text {rev }}$ and $-30 \mathrm{mV}$, and, above this, was outward, typical of $\mathrm{K}_{\mathrm{ATP}}$ [59] (Fig. 4d, difference current in red). When $\mathrm{Cs}^{+}$-containing solutions (principal charge carrier, $\mathrm{Cs}^{+}$intra- and extracellularly) were used, diazoxide failed to induce membrane currents in quiescent primary rat microglia (Fig. 4d, lower record). $\mathrm{As}^{-{ }^{+}}$blocks $\mathrm{K}^{+}$but not non-selective cation channels, these findings are consistent with the expression of $\mathrm{K}_{\mathrm{ATP}}$ but not Sur1Trpm4 channels in quiescent microglia.

By contrast, TLR4-activated microglia exhibited currents attributable to Sur1-Trpm4. Currents recorded in $\mathrm{Cs}^{+}$-containing solutions were activated by the Sur1 agonist, diazoxide, had a reversal potential of $\sim 0 \mathrm{mV}$, and were blocked by both the Sur1 antagonist, glibenclamide, and the Trpm4 antagonist, 9-phenanthrol (Fig. 4e). In these cells, $5 \mu \mathrm{M}$ glibenclamide or $10 \mu \mathrm{M}$ 9phenanthrol blocked $>90 \%$ of the diazoxide-induced inward current at $-50 \mathrm{mV}$ (seven and six cells, respectively).

Together, these findings indicated that TLR4 activation of microglia induces a switch from a quiescent phenotype expressing $\mathrm{K}_{\mathrm{ATP}}$ channels to an activated phenotype with de novo upregulation of Sur1-Trpm4 channels. 

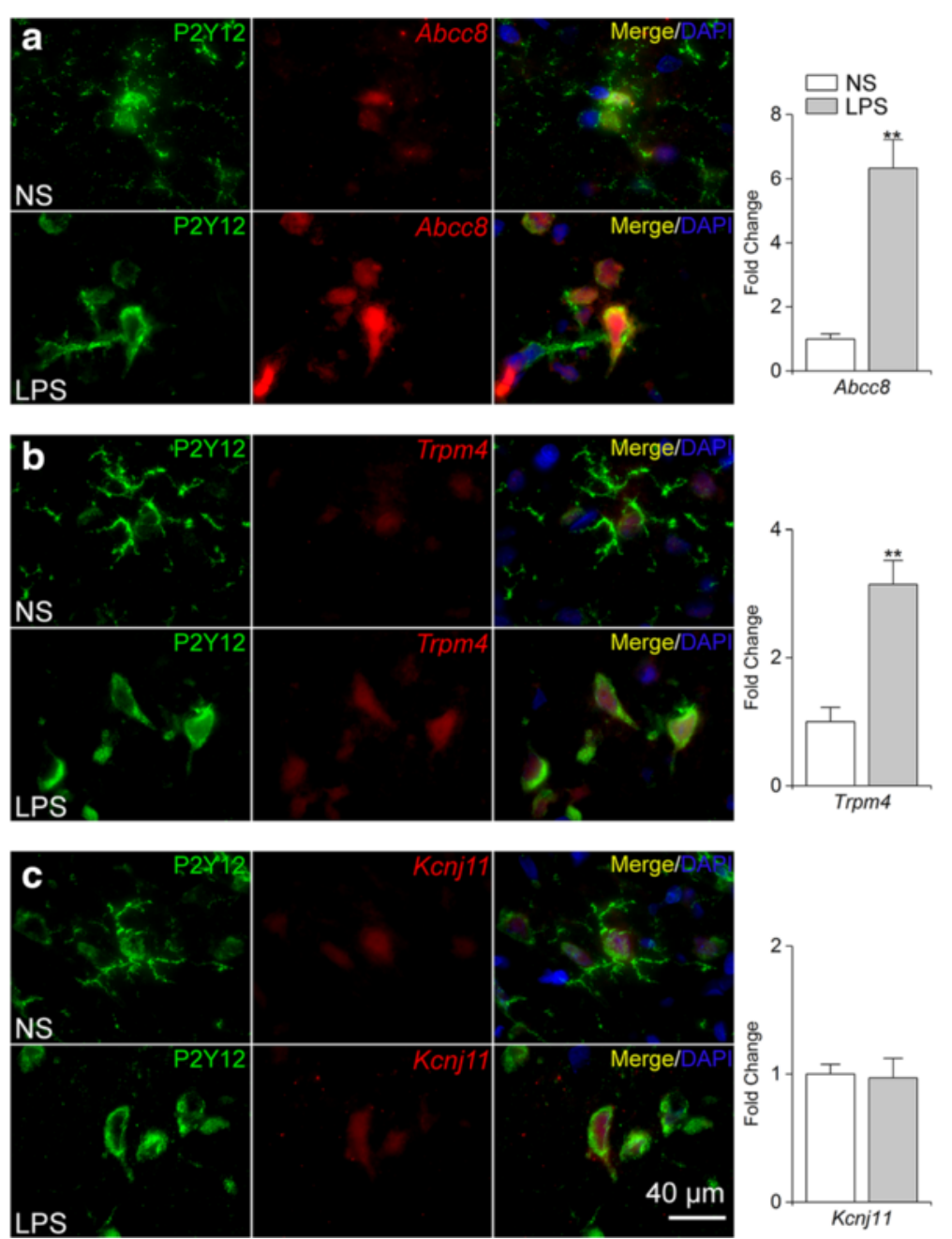

Fig. 2 Upregulation of Abcc8 and Trpm4 mRNA in TLR4-activated rat microglia in vivo. a-c Immunofluorescence labeling of P2Y12 ${ }^{+}$microglia (green) and fluorescence in situ hybridization (FISH) of mRNA transcripts of Abcc8, Trpm4, or Kcnj11 (red), following intrastriatal infusion (0.5 $\mu \mathrm{L} / \mathrm{h}$ ) of normal saline (NS) or LPS (5 $\mathrm{mg} / \mathrm{day})$ for $24 \mathrm{~h}$ (LPS); nuclei labeled with DAPI (blue); bar graphs quantification of microglial expression of Abcc8, Trpm4, or Kcnj11, expressed as fold change normalized to values with NS infusion; five replicates; ${ }^{* *} p<0.01$

\section{TLR4 activation causes de novo Sur1-Trpm4 channel upregulation in $\mathrm{N} 9$ microglia}

The N9 microglial cell line shares many phenotypic characteristics with primary microglia [60]. Here, we studied N9 microglia to determine whether they too would respond to TLR4 activation by upregulating Sur1Trpm4 channels and to examine downstream signaling involving Sur1-Trpm4.

As with primary cells, TLR4 activation of N9 microglia induced an activated phenotype heralded by a change in morphology to amoeboid (Fig. 5a). Following TLR4 activation for $24 \mathrm{~h}, A b c c 8$ and Il-6 mRNA were significantly elevated (fold change, $2.57 \pm 0.13$ and $12.2 \pm 1.9$, respectively, $p<0.05$ ) (Fig. 5b). No change in mRNA abundance was observed for either Trpm4 or Kcnj11.

Immunoprecipitation/immunoblot of whole cell lysate from N9 microglia showed minimal Sur1 expression under basal conditions and a significant increase in Sur1 following TLR4 activation (fold change, $2.68 \pm 0.34, p<$ 0.05) (Fig. 5c). By contrast, basal expression of Trpm4 was prominent, and no change in Trpm 4 expression was observed following TLR4 activation (Fig. 5c). Coimmunoprecipitation revealed a significant increase in co-associated Sur1 and Trpm4 following TLR4 activation (fold change, $3.83 \pm 1.3, p<0.05$, Fig. $5 \mathrm{c}$ ). Thus, in N9 cells, high basal levels of Trpm4 appeared to be sufficient for de novo formation of Sur1-Trpm4 following TLR4 activation.

Patch clamp recordings were used to determine whether co-assembled Sur1-Trpm4 heteromers formed functional channels in TLR4-activated N9 microglia. In quiescent N9 microglia, when $\mathrm{Cs}^{+}$was used as the principal charge carrier, the Sur1 agonist, diazoxide failed to induce membrane currents, consistent with the absence 

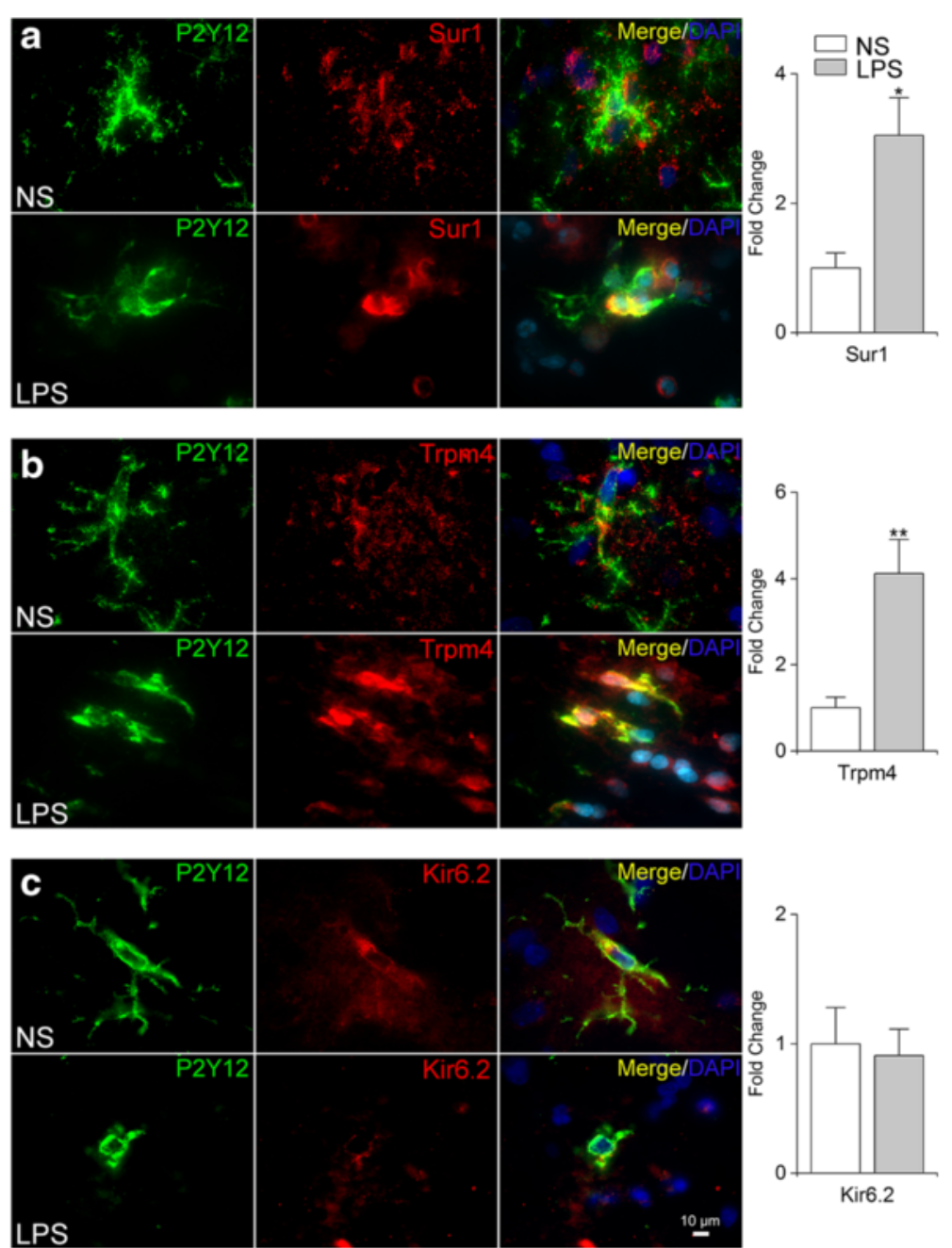

Fig. 3 Upregulation of Sur1 and Trpm4 protein in TLR4-activated rat microglia in vivo. a-c Double immunofluorescence labeling of microglia (P2Y12, green) and Sur1, Trpm4, or Kir6.2 (red), following intrastriatal infusion (0.5 $\mu \mathrm{L} / \mathrm{h})$ of normal saline (NS) or LPS (5 $\mu \mathrm{g} /$ day) for $24 \mathrm{~h}$ (LPS); nuclei labeled with DAPI (blue); representative high magnification $(\times 100)$ images are shown; bar graphs quantification of microglial expression of Sur1, Trpm4, or Kir6.2, expressed as fold change normalized to values with NS infusion; five replicates; ${ }^{*} p<0.05 ;{ }^{* *} p<0.01$

of Sur1-regulated non-selective cation channels, and similar to findings in primary microglia. By contrast, TLR4activated microglia exhibited $\mathrm{Cs}^{+}$currents induced by diazoxide that had a reversal potential of $\sim 0 \mathrm{mV}$ and were blocked by the Sur1 antagonist, glibenclamide (Fig. 5d-f), consistent with Sur1-Trpm4 channels [41]. As expected, the change in microglial phenotype was accompanied by an increase in cell volume (Fig. 5g) [19].

Thus, TLR4 activation in N9 microglia resulted in a switch from a quiescent to an activated phenotype that was accompanied by de novo upregulation of Sur1-Trpm4 channels, similar to findings in primary microglia.

\section{Role of Sur1-Trpm4 in TLR4-activated microglia} Sur1-Trpm4 is a negative regulator of $\mathrm{Ca}^{2+}$ entry

Numerous ligand-receptor interactions in microglia have been shown to give rise to $\mathrm{Ca}^{2+}$ influx $[18,20,21]$, including LPS [50, 58, 61, 62]. Here, exposure of quiescent microglia to LPS induced an initial rise in $\left[\mathrm{Ca}^{2+}\right]_{\mathrm{i}}$ followed by plateau phase [58, 62] (Fig. 6a). Quiescent microglia were characterized by minimal dynamic changes in $\left[\mathrm{Ca}^{2+}\right]_{\mathrm{i}}$ over time, whereas microglia activated by TLR4 ligation for $24 \mathrm{~h}$ exhibited an oscillatory pattern of $\left[\mathrm{Ca}^{2+}\right]_{\mathrm{i}}$ (Fig. 6b, left panel, single cell traces), a phenomenon previously shown to depend on Trpm4 [63]. $\mathrm{Ca}^{2+}$ oscillation was abolished by TAK-242 inhibition of TLR4 signaling (Fig. 6b, right panel). LPS-induced increases in $\left[\mathrm{Ca}^{2+}\right]_{\mathrm{i}}[64,65]$, as well as $\mathrm{Ca}^{2+}$ oscillation $[66,67]$, previously were shown to be mediated by SKF-96395-sensitive $\mathrm{Ca}^{2+}$ entry channels. Here, in N9 microglia, we found that LPS-induced oscillations also were abrogated by SKF-96395 (Fig. 6b, right panel).

In cells with $\mathrm{Ca}^{2+}$ entry mediated by non-voltageoperated ROCE and SOCE channels, Sur1-Kir6.2 (K $\left.{ }_{\text {ATP }}\right)$ 

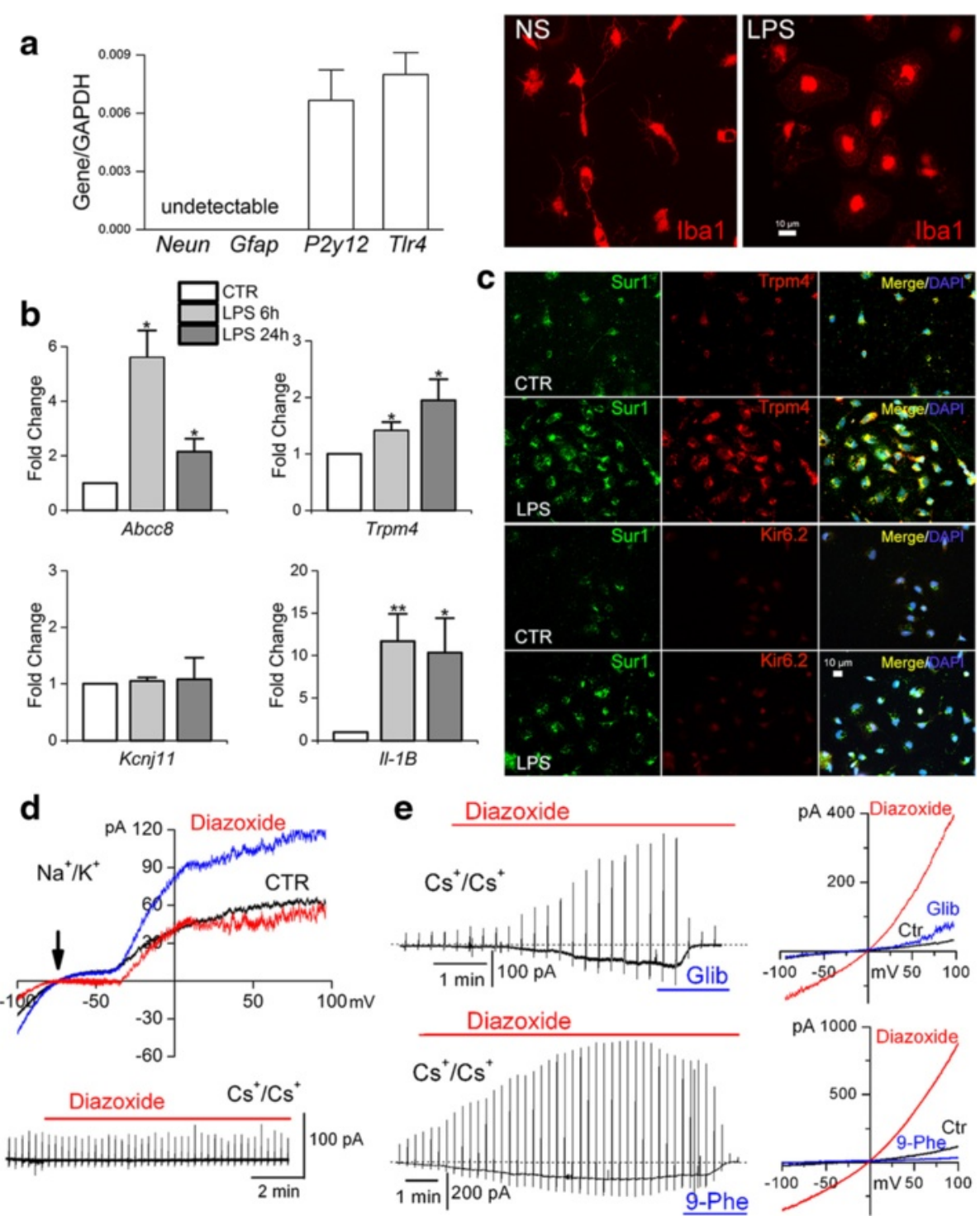

Fig. 4 Upregulation of Sur1-Trpm4 channels in TLR4-activated primary rat adult microglia. a qPCR analysis of isolated cells (left) showing expression of microglial P2y12 and T/r4, and no expression of neuronal Neun or astrocytic Gfap; data are from three independent replicates; also shown are representative immunofluorescence images of $\mathrm{Iba}^{+}{ }^{+}$isolated microglia under control conditions (normal saline, NS) versus $24 \mathrm{~h}$ after TLR4 ligation by LPS (1 $\mu \mathrm{g} / \mathrm{mL}$ ). b Fold change in mRNA for Abcc8, Trpm4, and Kcnj11 in primary cultured adult microglia activated by ligation of TLR4 with LPS (1 $\mu \mathrm{g} / \mathrm{mL})$ for $24 \mathrm{~h}$; induction of $11-1 \beta$ mRNA was used as a positive control; ten replicates; ${ }^{*} p<0.05$; ${ }^{* *} p<0.01$. c Representative immunofluorescence images of primary cultured adult microglia showing expression of Sur1, Trpm4, and Kir6.2 protein under control (CTR) conditions and after ligation of TLR4 with LPS $(1 \mathrm{\mu g} / \mathrm{mL})$ for $24 \mathrm{~h}$. $\mathbf{d}$ Whole-cell currents in quiescent primary cultured microglia recorded with physiological solutions (upper) and with Cs ${ }^{+}$-containing solutions (lower) during ramp pulses, shown at high (upper) and low (lower) temporal resolution; Sur1-activation by diazoxide yielded the difference current attributable to $\mathrm{K}_{\text {ATP }}$ (red). e Whole-cell currents in TLR4-activated primary cultured microglia recorded with $\mathrm{Cs}^{+}$-containing solutions during ramp pulses, shown at low (left) and high (right) temporal resolution, with Sur1-activation by diazoxide $(100 \mu \mathrm{M})$, and blockade by glibenclamide $(5 \mu \mathrm{M})$ (upper) or 9-phenanthrol $(10 \mu \mathrm{M})$ (lower); the tracings in $\mathbf{d}$ and $\mathbf{e}$ are representative of six to eight cells per condition, with ramp pulses -100 to $+100 \mathrm{mV}$ in $500 \mathrm{~ms}$, repeated every $15 \mathrm{~s}$; holding potential, $-50 \mathrm{mV}$

channels on the one hand, and Trpm4 or Sur1-Trpm4 channels on the other hand, are expected to have opposite effects on $\mathrm{Ca}^{2+}$ entry, since opening of Sur1-Kir6.2 $\left(\mathrm{K}_{\mathrm{ATP}}\right)$ channels hyperpolarizes the cell membrane, whereas opening of Trpm4 or Sur1-Trpm4 depolarizes the cell membrane [26-31]. In quiescent microglia, diazoxide activation of Sur1 increased $\left[\mathrm{Ca}^{2+}\right]_{\mathrm{i}}$, and glibenclamide inhibition of Sur1 decreased $\left[\mathrm{Ca}^{2+}\right]_{\mathrm{i}}$ (Fig. 6c, red and green symbols). Opposite responses were found in TLR4-activated microglia, with diazoxide activation of Sur1 decreasing $\left[\mathrm{Ca}^{2+}\right]_{\mathrm{i}}$ and glibenclamide inhibition of Sur1 increasing $\left[\mathrm{Ca}^{2+}\right]_{\mathrm{i}}$ (Fig. 6d, red and green symbols). 
a
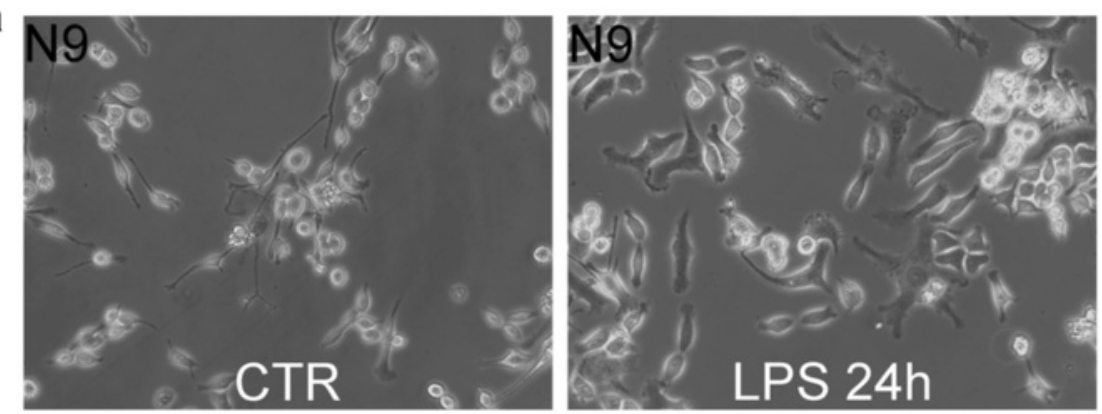

b

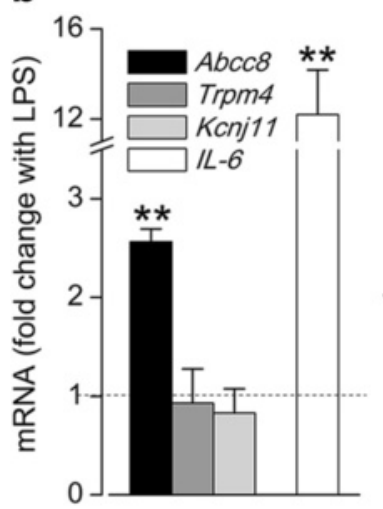

c $\quad$ CTR
LPS
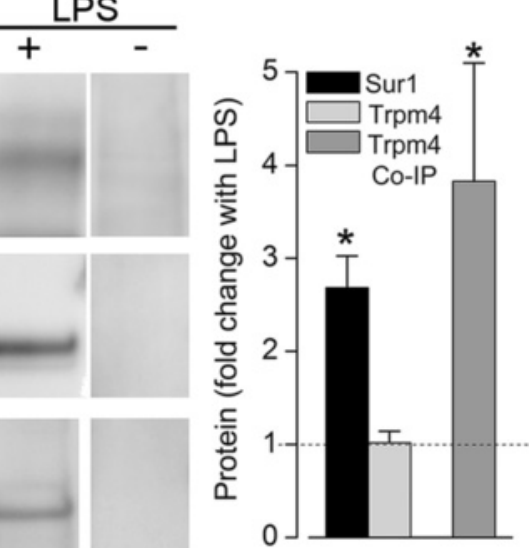

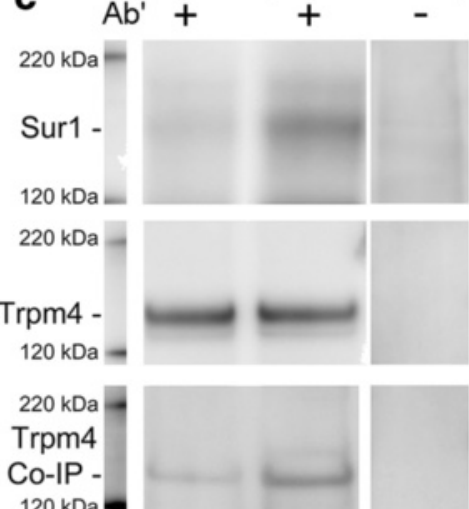

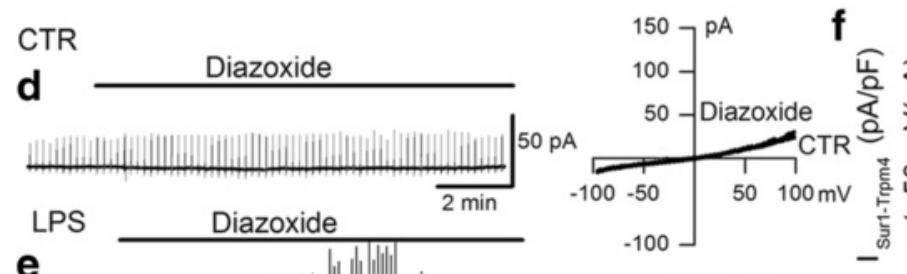
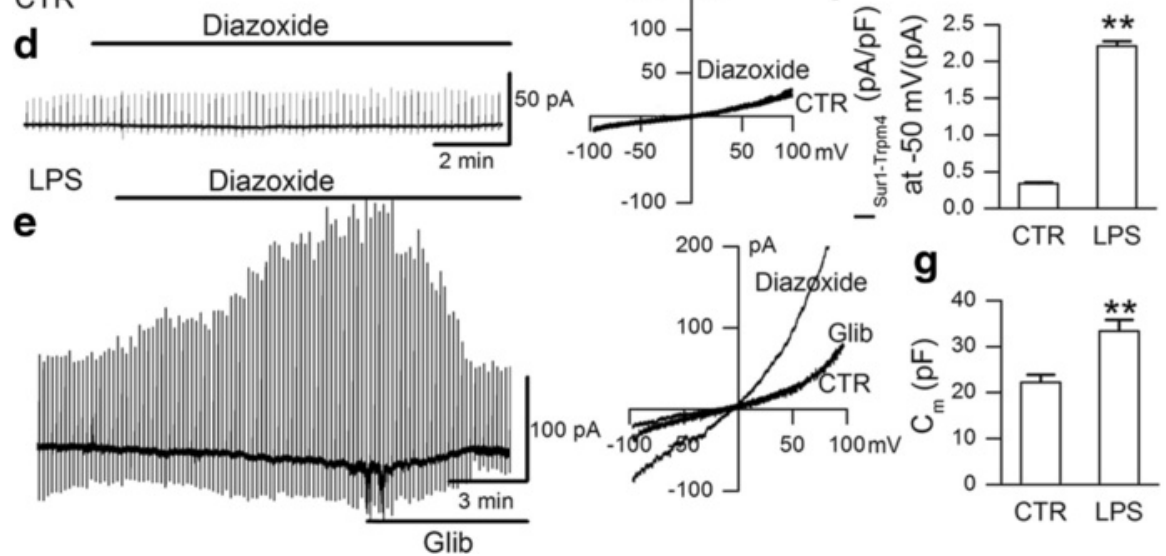

g

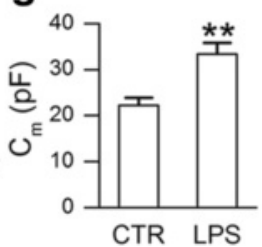

Fig. 5 Upregulation of Sur1-Trpm4 channels in TLR4-activated murine N9 microglia. a Phase contrast images of N9 microglia under control (CTR) conditions (left) and $24 \mathrm{~h}$ after LPS treatment $(1 \mu \mathrm{g} / \mathrm{mL}$ ) (right). b Change in mRNA for Abcc8, Trpm4, and Kcnj11 in N9 microglia activated by ligation of TLR4 with LPS $(1 \mathrm{\mu g} / \mathrm{mL})$ for 24 h; induction of $11-6$ mRNA was used as a positive control; six replicates; ${ }^{* *} p<0.01$; the dotted line indicates basal level of expression. c Immunoblots (left panel) and quantification (right panel) for Sur1 and Trpm4 of immunoisolates from N9 microglial lysates under control conditions (CTR) and following TLR4 activation for $24 \mathrm{~h}$ (LPS), with omission of IP antibody (Ab') shown as a negative control; for coimmunoprecipitation (CO-IP), immunoisolation was performed using anti-Sur1 antibody and immunoblot was performed using anti-Trpm4 antibody; three replicates; ${ }^{*} p<0.05$. d, e Whole-cell $\mathrm{Cs}^{+}$currents at low (left) and high (right) temporal resolution during ramp pulses $(-100$ to $+100 \mathrm{mV}$ in $500 \mathrm{~ms}$, repeated every $15 \mathrm{~s}$; holding potential, $-50 \mathrm{mV}$ ) in control N9 microglia (CTR) and N9 microglia after TLR4 activation by LPS (1 $\mu \mathrm{g} / \mathrm{mL})$ for $24 \mathrm{~h}$; Sur1 was activated by diazoxide $(100 \mu \mathrm{M})$ and inhibited by glibenclamide $(5 \mu \mathrm{M})$. $\mathbf{f}$ Magnitude of the inward current density at $-50 \mathrm{mV}\left(I_{\text {sur1-Trpm } 4)}\right.$ activated by diazoxide in control versus TLR4-activated N9 microglia; same experiment as in $\mathbf{d}$ and $\mathbf{e} . \mathbf{g}$ Magnitude of the membrane capacitance $\left(C_{\mathrm{m}}\right)$ in control versus TLR4-activated N9 microglia; same experiment as in $\mathbf{d}$ and $\mathbf{e}$; 14-16 cells/condition

In both quiescent and TLR4-activated microglia, 9phenanthrol inhibition of Trpm4 [68] increased $\left[\mathrm{Ca}^{2+}\right]_{\mathrm{i}}$ (Fig. 6c,d, blue symbols). Together, these findings are consistent with the interpretation that (i) both quiescent and activated N9 microglia express Trpm4 [58], which functions to limit $\mathrm{Ca}^{2+}$ influx [29, 69, 70]; (ii) quiescent microglia express Sur1-Kir6.2 ( $\left.\mathrm{K}_{\text {АTP }}\right)$ channels [32-34], whose activation leads to hyperpolarization, which 

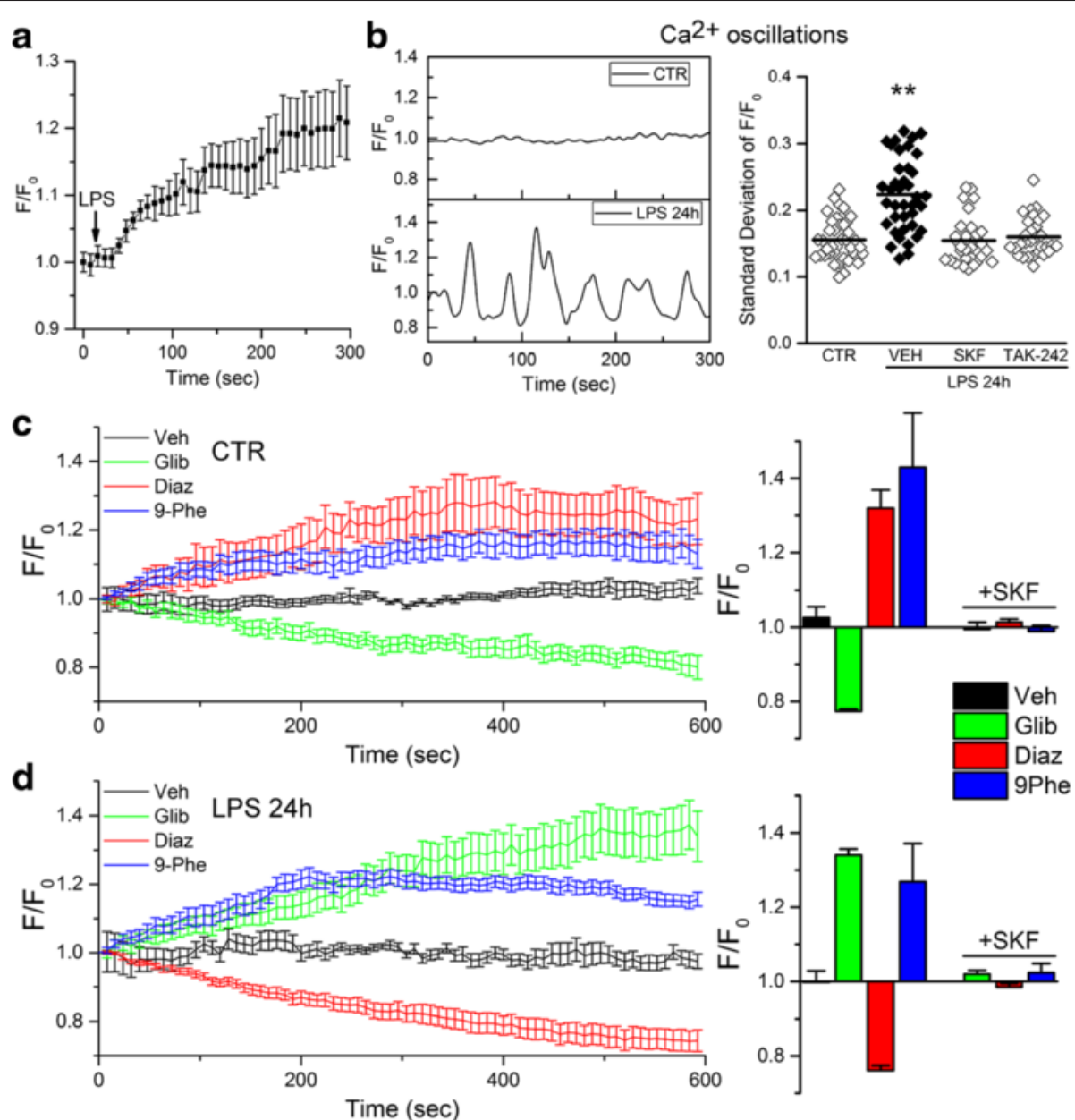

Fig. 6 Sur1-Trpm4 is a negative regulator of SKF-96395-sensitive Ca ${ }^{2+}$ entry channels in murine N9 microglia. a Acute effect of LPS (1 $\left.\mu \mathrm{g} / \mathrm{mL}\right)$ on $\left[\mathrm{Ca}^{2+}\right]_{\mathrm{i}}$ in $\mathrm{N} 9$ microglia, expressed as fluorescence $(F)$ over baseline $\left(F_{0}\right)$; data were obtained from ten cells per individual experiment; data shown are average responses of four independent replicates; the black arrow shows the time of LPS application. $\mathbf{b}$ Representative single cell traces of F/ $F_{0}$ in control (CTR) and TLR4-activated (LPS 24 h) N9 microglia (left); also shown is the quantification of $\mathrm{Ca}^{2+}$ oscillations (right), expressed as the time series rolling standard deviation of $F / F_{0}$, in CTR cells and in TLR4-activated cells treated with vehicle (VEH), the $\mathrm{Ca}^{2+}$ entry antagonist, SKF-

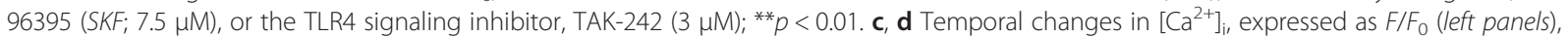
and magnitude of $F / F_{0}$ at the termination of recording (right panels), in control (c) and N9 microglia after TLR4-activation by LPS (1 $\left.\mu \mathrm{g} / \mathrm{mL}\right)$ for $24 \mathrm{~h}$ (d), following application of vehicle (Veh), the Sur1 antagonist, glibenclamide (Glib; $30 \mu \mathrm{M}$ ), the Sur1 agonist, diazoxide (Diaz; $100 \mu \mathrm{M})$, the Trpm4 antagonist or 9-phenanthrol (9Phe; $5 \mu \mathrm{M})$; also shown is the magnitude of $F / F_{0}$ after application of the $\mathrm{Ca}^{2+}$ entry antagonist, SKF-96395 $(S K F ; 7.5 \mu \mathrm{M})($ right panels); the time of drug application was coincident with the start of recording; data were obtained from ten cells per individual experiment (left); average data collected at the end of 10 min recording from thee to five independent replicates are shown (right)

increases the inward driving force for $\mathrm{Ca}^{2+}$; and (iii) TLR4-activated microglia express Sur1-Trpm4 channels, whose activation leads to depolarization, which decreases the inward driving force for $\mathrm{Ca}^{2+}[26,30]$.

\section{Sur1-Trpm4 regulates NFATc1}

The phenotype of N9 microglia is regulated by $\left[\mathrm{Ca}^{2+}\right]_{\mathrm{i}}$ and the transcription factor, NFAT, similar to TLR4activated primary cultured microglia [71-73]. NFATc1 (NFAT2) is the isoform of NFAT that regulates the proinflammatory phenotype, including NOS2 expression, in activated microglia [14, 72]. NFAT is normally phosphorylated and sequestered in the cytoplasm. Nuclear translocation occurs following dephosphorylation by the $\mathrm{Ca}^{2+}$-sensitive phosphatase, calcineurin (CN) [74].

We evaluated NFATc1 activation in N9 microglia (Fig. $7 \mathrm{a}-\mathrm{c})$. Control cells were characterized by NFATc1 immunoreactivity that was confined mostly to the cytoplasm. Increasing $\left[\mathrm{Ca}^{2+}\right]_{\mathrm{i}}$ using the $\mathrm{Ca}^{2+}$ ionophore, A23187, significantly increased nuclear NFATc1. TLR4 activation for $24 \mathrm{~h}$, which increases $\left[\mathrm{Ca}^{2+}\right]_{\mathrm{i}}$ (Fig. 6a,b), also induced nuclear translocation of NFATc1 [63]. In the presence of LPS, inhibition of $\mathrm{Ca}^{2+}$ influx by SKF96395, which previously was shown to inhibit NFATc3 nuclear translocation [75], here was shown to inhibit NFATc1 nuclear translocation. 


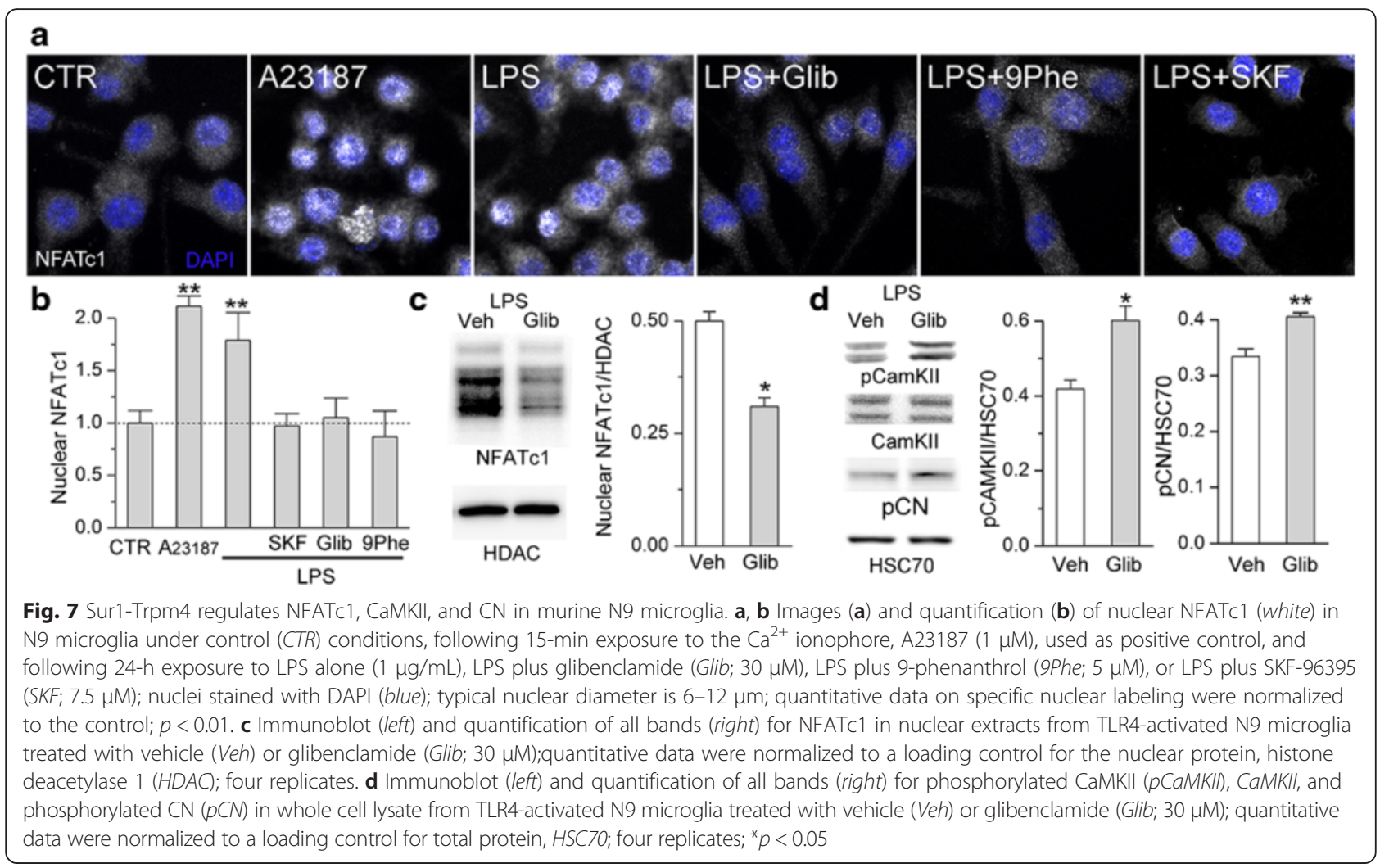

Since inhibition of Sur1-Trpm4 by glibenclamide or 9phenanthrol increases $\left[\mathrm{Ca}^{2+}\right]_{\mathrm{i}}$ (Fig. 6d), and since increasing $\left[\mathrm{Ca}^{2+}\right]_{\mathrm{i}}$ activates NFAT, we expected that Sur1-Trpm4 channel inhibition would increase NFAT nuclear translocation. Unexpectedly, glibenclamide and 9-phenanthrol inhibited LPS-induced nuclear translocation of NFATc1 (41 and $51 \%$ reduction vs. LPS alone) (Fig. 7a, b). Nuclear immunoblots confirmed that glibenclamide inhibition of Sur1-Trpm4 reduced the nuclear accumulation of NFATc1 after TLR4 activation (38\% reduction vs. LPS alone, Fig. 7c).

\section{Sur1-Trpm4 inhibition activates CaMKII in microglia}

One possible explanation for the unexpected finding that glibenclamide inhibition of Sur1-Trpm4 reduced nuclear accumulation of NFATc1 is that the increase in $\left[\mathrm{Ca}^{2+}\right]_{i}$ induced by channel blockade caused activation of CaMKII. In vascular smooth muscle cells and cardiac myocytes, increasing $\left[\mathrm{Ca}^{2+}\right]_{\mathrm{i}}$ activates not only $\mathrm{CN}$ but also CaMKII, with higher levels of $\mathrm{Ca}^{2+} /$ calmodulin being required to activate CaMKII, compared to CN $[16,76]$. Importantly, activated CaMKII negatively regulates NFAT signaling by phosphorylating $\mathrm{CN}$ at Ser197, which inhibits its phosphatase activity [76], thus allowing NFAT to be more phosphorylated and so maintained within the cytoplasm $[16,76,77]$. Here, we found that in TLR4-activated N9 microglia, glibenclamide inhibition of Sur1-Trpm4, which we showed previously augments $\left[\mathrm{Ca}^{2+}\right]_{\mathrm{i}}$, led to a significant increase in phosphorylated CaMKII (pCaMKII) (30\% increase vs. LPS alone, Fig. 7d) and a significant increase in phosphorylated $\mathrm{CN}$ ( $\mathrm{pCN})$ (23\% increase vs. LPS alone, Fig. 7d), consistent with the reduced nuclear translocation of NFATc1 observed with glibenclamide.

\section{Sur1-Trpm4 regulates binding of NFATc1 to the Nos2 promoter}

NFATc1 is a key transcriptional regulator of Nos 2 gene expression. Strong induction of Nos 2 mRNA was observed in TLR4-activated microglia (Fig. 8a). As reported [61], treatment with the $\mathrm{Ca}^{2+}$ chelator, BAPTA-AM, significantly attenuated Nos 2 induction (66 \% reduction versus LPS alone). Inhibition of NFAT, either indirectly by FK506 inhibition of CN, or directly by $11 \mathrm{R}-$ VIVIT [72, 78], significantly reduced the induction of Nos2 mRNA (68 and $46 \%$ reduction, respectively).

Inhibition of Sur1 by glibenclamide dose dependently reduced Nos2 mRNA induction in TLR4-activated microglia, with an $\mathrm{EC}_{50}$ of $26 \mu \mathrm{M}$ (Fig. 8a). An MTT cell viability assay showed that glibenclamide was not cytotoxic across the range of concentrations tested (data not shown). Since these experiments were carried out in the presence of $5 \% \mathrm{FBS}$, and since glibenclamide is $99 \%$ protein bound [48], these data suggest an apparent $\mathrm{EC}_{50}$ value of $\sim 260 \mathrm{nM}$ free glibenclamide. The Trpm4 

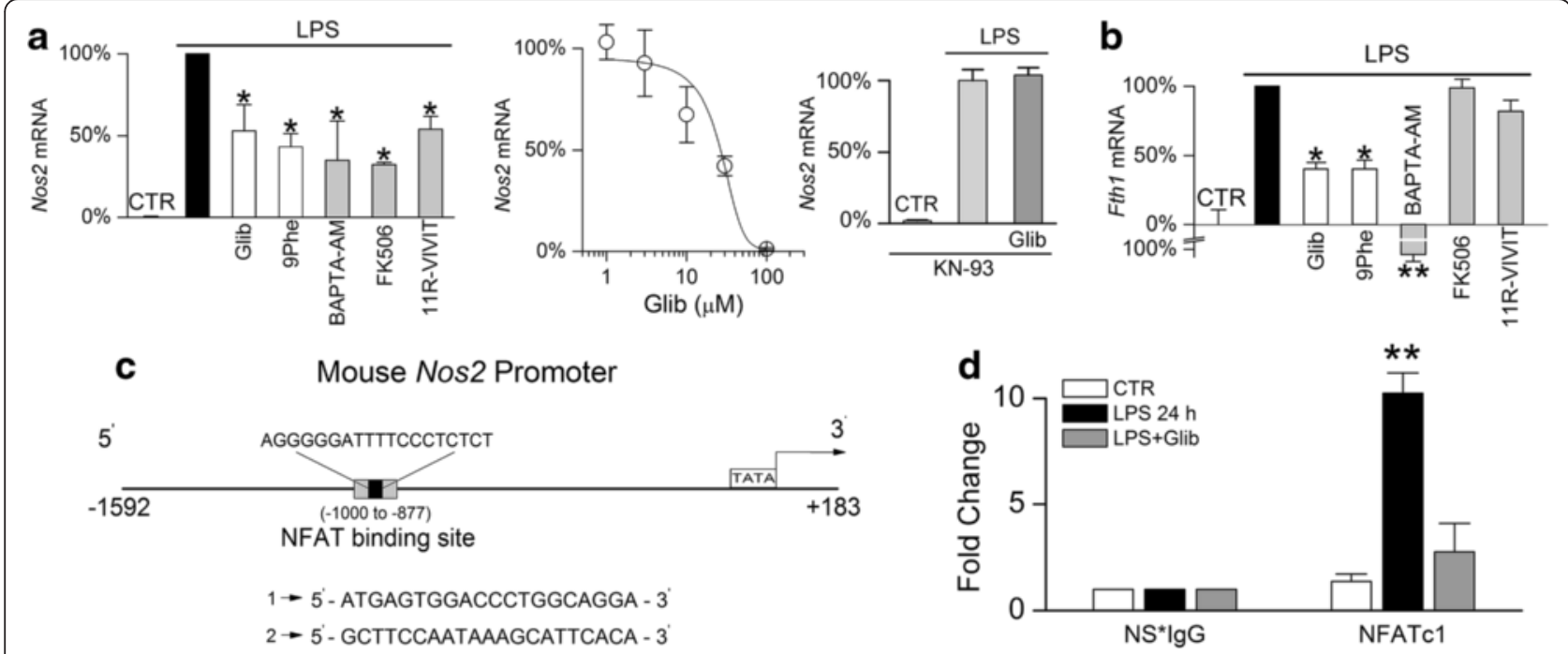

Fig. 8 Sur1-Trpm4 regulates the binding of NFATC1 to the Nos2 promoter in murine N9 microglia. a Percent change in mRNA for Nos2 in N9 microglia (left) under control (CTR) conditions, or following 24-h exposure to LPS alone (1 $\mu \mathrm{g} / \mathrm{mL})$, LPS plus glibenclamide (Glib; 30 MM), LPS plus

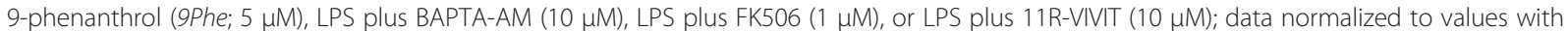
LPS alone; five replicates; ${ }^{*} p<0.05$; also shown (middle) is the concentration-response relationship for LPS induction of Nos 2 mRNA versus glibenclamide concentration; $\mathrm{EC}_{50}, 26 \mu \mathrm{M}$; experiments performed in $5 \%$ fetal bovine serum; three replicates; also shown (right) is the absence of effect of glibenclamide on Nos2 mRNA induction in the presence of the CaMKII inhibitor, KN-93; three replicates. $\mathbf{b}$ Percent change in mRNA for Fth1 in N9 microglia under control (CTR) conditions or following 24-h exposure to LPS alone (1 $\mu \mathrm{g} / \mathrm{mL})$, LPS plus glibenclamide (Glib; 30 MM), LPS

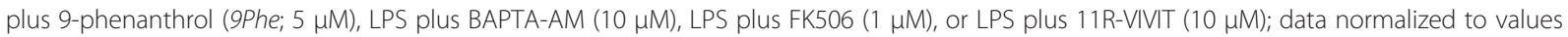
with LPS alone, which represented a four to fivefold increase; five replicates; ${ }^{*} p<0.05 ;{ }^{* *} p<0.01$. c Schematic of the mouse Nos 2 promoter; gray box indicates the region from -1000 to -877 used for PCR, with sequences of primers used to amplify immunoisolated DNA shown below; this region of the promotor contains an NFAT binding site (black box; sequence shown above). d Quantification of immunoisolated DNA following ChIP with an anti-NFATC1 antibody or species-matched non-specific lgG (NS*IgG) from N9 microglia under control (CTR) conditions or following 24-h exposure to LPS alone $(1 \mu \mathrm{g} / \mathrm{mL})$ or LPS plus glibenclamide (Glib; $30 \mu \mathrm{M})$; three replicates; ${ }^{* *} p<0.01$

inhibitor, 9-phenanthrol, also significantly reduced Nos2 mRNA induction in TLR4-activated microglia (57 \% reduction) (Fig. 8a). Notably, the inhibition of Nos 2 mRNA induction by glibenclamide was prevented by blockade of CaMKII with KN-93 (Fig. 8a). Thus, the TLR4mediated induction of Nos 2 mRNA was sensitive to $\left[\mathrm{Ca}^{2+}\right]_{\mathrm{i}}$, NFAT, and Sur1-Trpm4, and the effect of Sur1 inhibition was dependent on CaMKII.

As a control, we evaluated the induction of ferritin $\mathrm{H}$ mRNA (Fth1), an inducible iron binding protein whose expression is $\mathrm{Ca}^{2+}$-dependent but NFAT-independent [79]. Similar to Nos2, Fth1 mRNA was strongly induced in TLR4-activated microglia and was sensitive to BAPTA-AM chelation of $\mathrm{Ca}^{2+}$ (Fig. 8b). In further support of Sur1-Trpm4 regulation of $\mathrm{Ca}^{2+}$-dependent transcriptional mechanisms, both glibenclamide and 9phenanthrol inhibition of Sur1-Trpm4 significantly reduced the induction of Fth1 mRNA in TLR4-activated microglia, although inhibition of NFAT by either FK506 or 11R-VIVIT had no effect (Fig. 8b).

ChIP experiments were carried out to determine whether the reduction of Nos 2 induction resulting from Sur1-Trpm4 inhibition was due to reduced binding of NFATc1 to the Nos 2 promoter. We independently verified the sequence of an NFAT binding site on the Nos2 promoter [14] (Fig. 8c). ChIP was performed from intact N9 cells using antibodies directed against NFATc1, with species-matched non-specific IgG (NS*IgG) used as a control. qPCR analysis of the immunoprecipitates was performed using primers generated to the -1000 to -877 region spanning the NFAT binding site. ChIP showed that LPS increased NFATc1 binding to the Nos2 promoter (Fig. 8d), consistent with TLR4 activation inducing NFAT-dependent Nos2 mRNA expression. Moreover, glibenclamide inhibition of Sur1-Trpm4 significantly attenuated NFATc1 binding to the Nos 2 promoter (Fig. 8d), consistent with Sur1-Trpm4 negatively regulating NFATc1. Together, these data indicated that inhibition of Sur1-Trpm4 decreases Nos 2 induction in TLR4-activated N9 microglia due to a reduction in NFATc1 binding to the Nos 2 promoter.

\section{Sur1-Trpm4 regulates induction of NOS2 protein and nitrite production}

Significantly less expression of NOS2 protein was observed in activated microglia treated with either glibenclamide or 9-phenanthrol (50 and $44 \%$ reduction, 

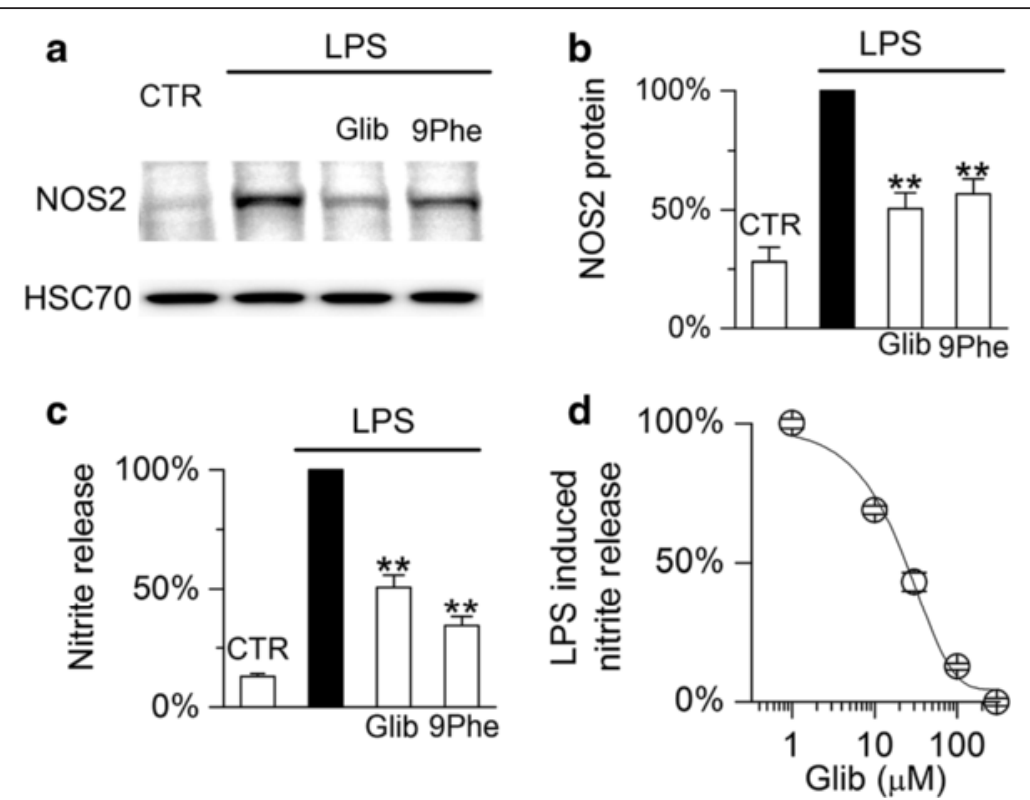

Fig. 9 Sur1-Trpm4 regulates induction of NOS2 protein in murine N9 microglia. a, b Immunoblot (a) and densitometric analysis (b) for NOS2 protein in N9 microglia under control (CTR) conditions or following 24-h exposure to LPS alone (1 $\mu \mathrm{g} / \mathrm{mL})$, LPS plus glibenclamide (Glib; 30 MM), or LPS plus 9-phenanthrol (9Phe; $5 \mu \mathrm{M}$ ); quantitative data were normalized to a loading control for total protein, HSC70, and to values with LPS alone; five replicates; ${ }^{* *} p<0.01$. c Percent nitrite in the medium of N9 microglial cultures under control (CTR) conditions or following $24-h$ exposure to LPS alone (1 $\mathrm{gg} / \mathrm{mL})$, LPS plus glibenclamide (Glib; $30 \mu \mathrm{M})$, or LPS plus 9-phenanthrol (9Phe; $5 \mu \mathrm{M})$; nitrite was measured using the Griess assay; data normalized to values with LPS alone, with maximum nitrite ranging from 8 to $13 \mu \mathrm{M}$ per experiment; three replicates. d Concentration-response relationship for LPS-induced nitrite in the medium versus glibenclamide; $\mathrm{EC}_{50}, 24 \mu \mathrm{M}$; experiments performed in $5 \%$ fetal bovine serum; three replicates

respectively) (Fig. 9a, b), in agreement with Sur1-Trpm4 inhibition reducing Nos 2 mRNA induction.

We also studied the effect of Sur1-Trpm4 inhibition on nitrite production, a functional measure of NOS2 activity, using the Griess assay. Both glibenclamide and 9phenanthrol significantly attenuated nitrite production in TLR4-activated microglia (Fig, 9c), consistent with Sur1-Trpm4 inhibition reducing TLR4-mediated upregulation of Nos2/NOS2. The effect of glibenclamide on nitrite production was dose dependent, with an $\mathrm{EC}_{50}$ value similar to that observed for Nos 2 mRNA induction (Fig. 9d).

\section{Abcc8-/- and Trpm4-/- protects against TLR4-mediated Nos2 induction in vivo}

The results of the foregoing experiments predict that gene silencing of $A b c c 8$ and of Trpm4 should protect against TLR4 activation in vivo. To test this hypothesis, sterile aCSF or LPS was injected into the striatum of adult WT, Abcc8-/- and Trpm4-/- mice to study the effect of TLR4 activation. Basal expression of CaMKII, CN, NFATc1, and NOS2 were similar in naïve (no injection) WT, Abcc8-/- and Trpm4-/- mice (data not shown). In WT mice, TLR4 activation increased NFATc1, consistent with NFATc1-mediated autoupregulation of Nfatc1 [80] and upregulation of NOS2 expression. By contrast, in Abcc8-/- and Trpm4-/mice, NFATc1 and NOS2 upregulation were significantly impaired (Fig. 10a, b), recapitulating the effect of glibenclamide in N9 microglia (Fig. 7a-c and Fig. 9).

Total levels of CaMKII and $\mathrm{CN}$ were unaffected by TLR4 ligation (Fig. 10a). LPS injection in WT mice resulted in minimal changes in $\mathrm{pCaMKII}$ and $\mathrm{pCN}$, but in Abcc8-/- and Trpm4-/- mice, LPS injection resulted in significant increases in pCaMKII and pCN (Fig. 10a, b). These findings accord with the reduced levels of NFATc1 and NOS2 expression in these genotypes and recapitulate the effect of glibenclamide in N9 microglia (Fig. 7d).

Finally, to determine whether the in vivo findings in the different murine genotypes were attributable to microglia, we evaluated the induction of Nos 2 and Fth1 mRNA in primary cultured microglia isolated from adult WT, Abcc8-/-, and Trpm4-/- mice. Isolated cells were highly enriched in microglia $(C d 11 b)$, with no detectable for astrocytes (glial fibrillary acidic protein (Gfap)) or neurons (Neun) (Fig. 10c). TLR4-mediated induction of both Nos 2 and Fth1 mRNA was significantly reduced in microglia derived from $A b c c 8-/-$ mice, by 70 and $39 \%$, respectively, and from Trpm4-/- mice, by 49 and $42 \%$, respectively (Fig. 10d), recapitulating the effect of glibenclamide and 9-phenanthrol in N9 microglia (Fig. 8). 


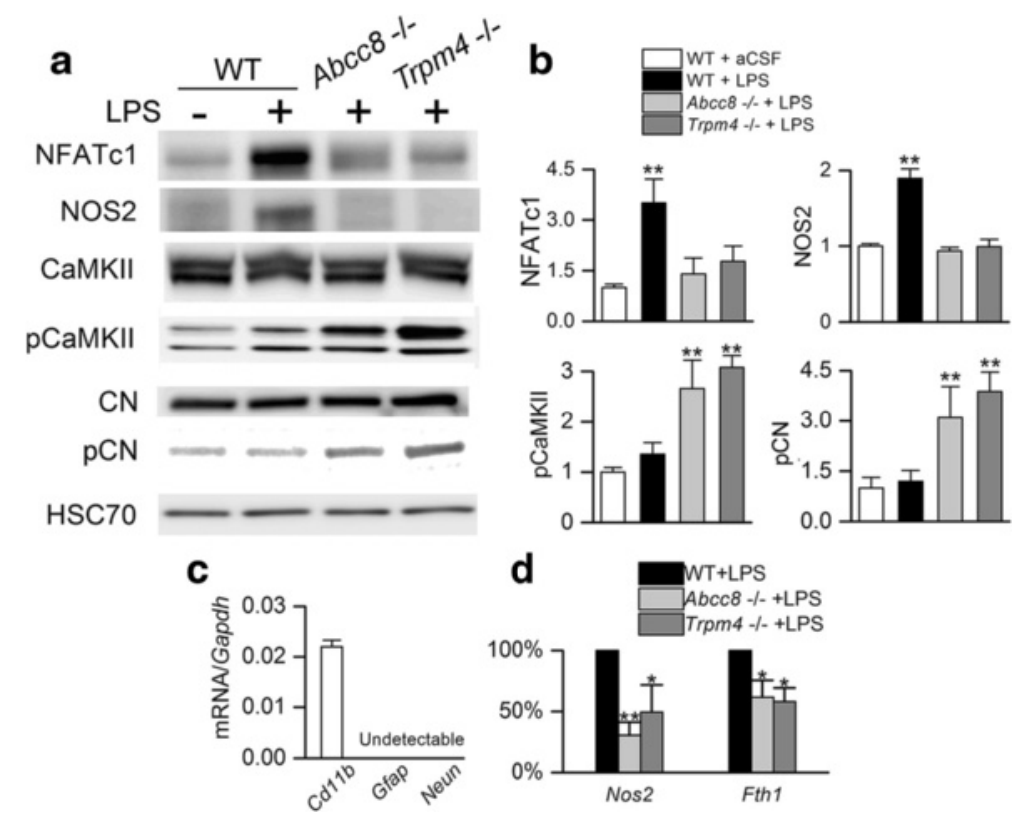

Fig. 10 Abcc8-/- and Trpm4-/- protects against TLR4-mediated NOS2 induction in murine microglia. a, b Immunoblots (a) and quantification (b) for NFATc1 (90 kDa isoform shown), NOS2 (130 kDa), pCaMKII ( $\alpha / \beta, 50 / 60 \mathrm{kDa}), \mathrm{CaMKIl}(\alpha / \beta, 50 / 60 \mathrm{kDa}), \mathrm{pCN}(60 \mathrm{kDa})$, and CN (60 kDa), for tissue homogenates from the striatum of wild-type (WT), Abcc8-/- and Trpm4-/- mice, $24 \mathrm{~h}$ after injection of aCSF (5 $\mu \mathrm{L})$ or LPS (5 $\mu \mathrm{L} ; 0.1 \mu \mathrm{g} / \mu \mathrm{L})$ into the striatum; gels were run separately for each protein analyzed; quantitative data were normalized to a loading control for total protein, HSC70; three replicates; ** $<0.01$. c Quantification of mRNA for microglial Cd11b, astrocytic Gfap, and neuronal Neun in freshly isolated microglia from mouse brain; data normalized to mRNA for Gapdh; three replicates. $\mathbf{d}$ Quantification of mRNA induction for Nos2 and Fth1 in primary cultured adult microglia from WT, Abcc8-/- and Trpm4-/- mice $24 \mathrm{~h}$ after exposure to LPS $(1 \mu \mathrm{g} / \mathrm{mL})$; data normalized to the response of LPS alone in WT microglia; three replicates; ${ }^{*} p<0.05$; ${ }^{* *} p<0.01$

\section{Discussion}

The major findings of the present study are that (i) TLR4-activated microglia exhibit de novo upregulation of Sur1-Trpm4 channels; (ii) microglial Sur1-Trpm4 channels act as negative regulators of SKF-96395sensitive $\mathrm{Ca}^{2+}$ entry channels; and (iii) whereas normally, TLR4 activation causes preferential activation of $\mathrm{CN} /$ NFATc1, resulting in induction of Nos2/NOS2, silencing or pharmacological blockade of Abcc8/Sur1 or Trpm4/ Trpm4 causes preferential activation of CaMKII, resulting in reduced NFAT activation and reduced induction of Nos2/NOS2. Our finding that Nos2/NOS2 induction is reduced via $\mathrm{pCaMKII-mediated} \mathrm{inhibition} \mathrm{of} \mathrm{CN} /$ NFATc1 in Abcc8-/- and Trpm4-/- mice constitutes a novel mechanism of ion channel-mediated control of $\mathrm{Ca}^{2+}$-dependent gene regulation $[81,82]$ (summarized in Fig. 11).

We validated N9 microglia as a tool to study the role of Sur1-Trpm4 in TLR4-activated microglia. This was important because cell signaling is difficult to study in primary microglial cultures, due to their relatively limited number, whereas microglial cell lines, which provide sufficient quantities of cells for cell signaling studies, cannot be assumed a priori to function identically to primary microglia $[60,83]$. There were several notable similarities between N9 cells and primary adult microglia following TLR4 activation: (i) the transition from a quiescent to an activated morphology; (ii) no induction of Kcnj11/Kir6.2; (iii) induction of $A b c c 8 / \mathrm{Sur1}$; (iv) de novo upregulation of functional Sur1-Trpm4 channels; (v) LPS-induced acute elevation of $\left[\mathrm{Ca}^{2+}\right]_{i}$ and oscillatory $\mathrm{Ca}^{2+}$ signaling $[50,58]$; and (vi) NFAT-dependent regulation of the pro-inflammatory phenotype [71-73]. A notable difference between N9 microglia and primary adult microglia was the lack of induction of Trpm4/Trpm4 in N9 cells by TLR4 activation. However, high basal expression of Trpm4 in N9 cells, which was not present in primary cells, may have masked or precluded Trpm4/ Trpm4 induction. Despite this difference, TLR4 activation in both N9 microglia and in primary adult microglia resulted in de novo upregulation of Sur1-Trpm4 channels. In addition, the effects of Sur1-Trpm4 inhibition or silencing on downstream TLR4 signaling were similar in N9 microglia, in primary cultured murine microglia, and in mouse brain. In all cases, NFAT activation and Nos $2 /$ NOS2 induction were markedly decreased by channel inhibition, even though the effects on $\mathrm{pCN}$ and $\mathrm{pCaM}$ KII appeared less robust in the N9 cells compared to the primary cells and tissues (Fig. 7 versus 10).

Ortega and colleagues [32] were the first to report an effect of glibenclamide on microglial activation in a rodent model of ischemic stroke. Utilizing the BV2 

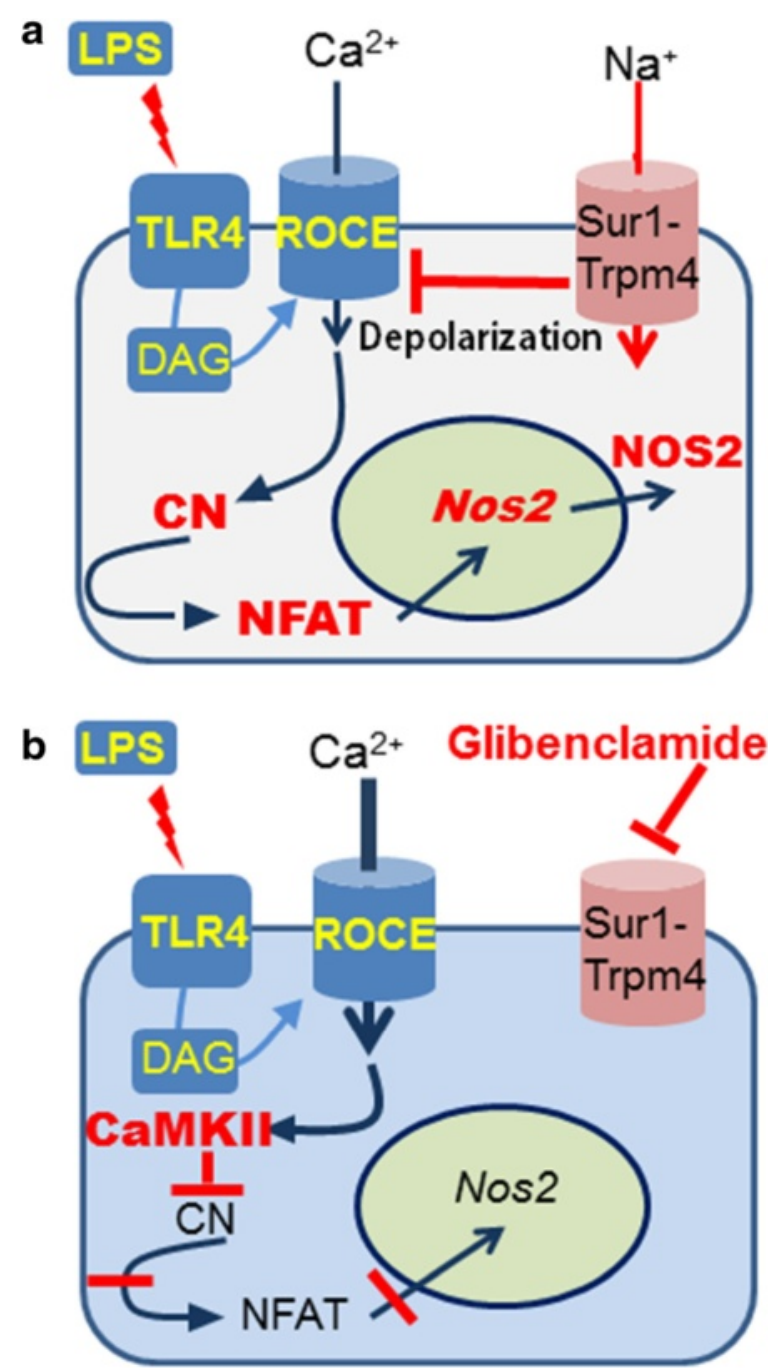

Fig. 11 Model of Sur1-Trpm4 regulation of $\mathrm{Ca}^{2+}$ entry, NFAT and Nos2/NOS2 in TLR4-activated microglia. $\mathbf{a}, \mathbf{b}$ Depiction of NFATmediated expression of Nos2/NOS2 in TLR4-activated microglia under normal conditions (a) and following inhibition of Sur1-Trpm4 by glibenclamide (b). Sur1-Trpm4 normally acts, via membrane depolarization, to regulate $\mathrm{Ca}^{2+}$ entry via SKF-96395-sensitive channels (e.g., ROCE), leading to activation of calcineurin (CN) and nuclear factor of activated T cells (NFAT), resulting in expression of Nos2/NOS2. When Sur1-Trpm4 is blocked by glibenclamide, excess $\mathrm{Ca}^{2+}$ enters the cell, preferentially activating CaMKII, which inhibits CN/NFAT and reduces the expression of Nos2/NOS2

microglial cell line, they reported induction of $A b c c 8 /$ Sur1 and Kcnj11/Kir6.2 following exposure to LPS + IFNy for $48 \mathrm{~h}$, as well as enhanced immunolabeling of microglia in vivo for subunits of Sur1-Kir6.2 (K $\left.\mathrm{K}_{\text {ATP }}\right)$ in cerebral ischemia. In their reports [32-34], they attributed the beneficial effects of glibenclamide in cerebral ischemia to inhibition of Sur1-Kir6.2 (K $\left.\mathrm{K}_{\mathrm{ATP}}\right)$. Here, studying microglia in vivo and primary cultured adult microglia in vitro, we observed currents in quiescent microglia that were clearly attributable to $\mathrm{K}_{\mathrm{ATP}}$ channels, and we confirmed the observations of Ortega et al. on Abcc8/Sur1 upregulation following TLR4 activation. However, we did not observe Kcnj11/Kir6.2 upregulation in any of our experiments with TLR4 activation, similar to Virgili et al. [84], who found no change in Kir6.2 in BV2 microglia or in primary cultured murine microglia exposed to LPS + IFN $\gamma$. Instead, we found that TLR4 activation induced de novo expression of Sur1-Trpm4 channels in both primary cultured adult microglia and in N9 cells.

In TLR4-activated microglia, the dominant Sur1regulated channel appears to be Sur1-Trpm4, not Sur1Kir6.2. First, we showed that Sur1-activation by diazoxide has opposite effects in TLR4-activated microglia compared to quiescent microglia. In quiescent microglia, Sur1 activation increases $\mathrm{Ca}^{2+}$ influx, consistent with Sur1Kir6.2 activation hyperpolarizing the cells and increasing the inward driving force for $\mathrm{Ca}^{2+}$. In TLR4-activated microglia, Sur1 activation decreases $\mathrm{Ca}^{2+}$ influx, consistent with Sur1-Trpm4 activation depolarizing the cells and decreasing the inward driving force for $\mathrm{Ca}^{2+}$. Second, blockade of Sur1 in TLR4-activated cells increases $\mathrm{Ca}^{2+}$ and increases pCaMKII, consistent with involvement of Sur1Trpm4 and ROCE/SOCE channels. Blockade of Sur1Kir6.2 could explain the latter finding, but only if VOCE channels were mediating $\mathrm{Ca}^{2+}$ influx. However, Trpm4 blockade, which hyperpolarizes the cell and should deactivate VOCE channels, led to an increase, not a decrease in $\left[\mathrm{Ca}^{2+}\right]_{\mathrm{i}}$, consistent with the absence of involvement of VOCE channels. The most parsimonious explanation for our combined observations is that Sur1-Trpm4 channels are the dominant contributors to the effects of Sur1modulation in TLR4-activated microglia. Sur1-Kir6.2 channels also may present, but the net effects of Sur1modulation in TLR4-activated microglia appear to be determined by Sur1-Trpm4.

Alterations in $\mathrm{Ca}^{2+}$ homeostasis contribute to microgliamediated progression of CNS disorders [19, 20, 61, 85, 86]. Regulation of $\left[\mathrm{Ca}^{2+}\right]_{\mathrm{i}}$ is critical for the initiation and maintenance of distinct transcriptional programs underlying potentially harmful microglial phenotypes [18-20]. Our data indicate that Sur1-Trpm4 channels are an important mechanism for regulating $\mathrm{Ca}^{2+}$ entry and downstream $\mathrm{Ca}^{2+}$-signaling in TLR4-activated microglia. Sur1-Trpm4 channels are activated by intracellular $\mathrm{Ca}^{2+}$, with a rise in $\left[\mathrm{Ca}^{2+}\right]_{\mathrm{i}}$ linking directly to membrane depolarization, providing negative feedback that opposes additional $\mathrm{Ca}^{2+}$ entry. Co-assembly with Sur1 increases the apparent sensitivity of Trpm4 to intracellular $\mathrm{Ca}^{2+}$, thereby strengthening Trpm4's role as a negative regulator of $\mathrm{Ca}^{2+}$ entry [41]. The Sur1-Trpm4 channel thus may be an important treatment target in degenerative diseases of the CNS mediated by TLR4-activated microglia. 
Calcineurin is a critical mechanism by which activated microglia shape their response to TLR4-ligation and control their phenotype $[19,87]$. The activation of CN/NFAT depends on the amplitude and duration of $\mathrm{Ca}^{2+}$ signals in combination with other $\mathrm{Ca}^{2+}$-dependent signals that may provide negative feedback $[88,89]$. NFAT is said to function as a "working memory" of $\mathrm{Ca}^{2+}$ signaling that is more efficiently activated by low-amplitude, repetitive oscillations in $\left[\mathrm{Ca}^{2+}\right]_{\mathrm{i}}$ than by continuous $\mathrm{Ca}^{2+}$ influx $[88,90]$. In accord with this, we observed that TLR4 activation for $24 \mathrm{~h}$ in N9 microglia led to oscillations of $\left[\mathrm{Ca}^{2+}\right]_{\mathrm{i}}$ accompanied by manifestations of the activated phenotype, including morphological changes, Sur1-Trpm4 upregulation, and Nos2/ NOS2 induction.

The paradoxical observations that inhibition of Sur1Trpm4 caused an elevation in $\left[\mathrm{Ca}^{2+}\right]_{i}$ but that it significantly reduced activation of NFATc1 led us to consider alternative $\mathrm{Ca}^{2+}$-dependent mechanisms regulating $\mathrm{CN}$. Importantly, sustained elevations of $\left[\mathrm{Ca}^{2+}\right]_{i}$ result in autonomous, persistent activation of CaMKII [77]. When CaMKII activity is augmented in vascular smooth muscle cells or in cardiac myocytes, the effects of increased $\mathrm{Ca}^{2+}$ on NFAT nuclear translocation are significantly attenuated, due to direct inhibition of $\mathrm{CN}$ [16, 76]. CaMKII-dependent processes were described recently in microglia [91], although CaMKII regulation of $\mathrm{CN}$ was not investigated. Inhibition/gene suppression of Sur1-Trpm4 following TLR4 activation resulted in significant increases in phosphorylated CaMKII (Fig. 7d) and in phosphorylated $\mathrm{CN}$ (Fig. 7d), consistent with this mechanism accounting for the attenuated NFATc1 translocation and reduced Nos $2 / \mathrm{NOS} 2$ induction that we observed.

Glibenclamide is not the only treatment to reduce NOS2 expression by activated microglia. Pretreatment of primary cultured neonatal microglia or BV2 cells with diazoxide prior to exposure to LPS + IFN $\gamma$ reduces NOS2 expression and nitrite production [84, 92]. Since diazoxide opens Sur1-regulated channels, whereas glibenclamide inhibits the same channels, our findings, as reported here, may seem to contradict published findings. However, our data showing that pharmacological inhibition of Sur1 reduces NOS2 were confirmed by similar results obtained with genetic inhibition of Sur1 via silencing of $A b c c 8$, both in vivo and in vitro. Notably, the molecular mechanism proposed for the anti-inflammatory effect of diazoxide involves a general reduction in the overall microglial response to activation signals [93], whereas the molecular mechanism that we propose for the anti-inflammatory effect of glibenclamide involves blockage of CN/NFATsignaling after microglial activation (Fig. 11). Thus, Sur1active drugs with different mechanisms of action may affect different aspects of the overall microglial inflammatory response, yet bring about a similar endpoint.
An important property of the Sur1-Trpm4 channel is that both subunits, Sur1 and Trpm4, are required for the manifestation of its pathological effects. This pathognomonic property was first described in an animal model of traumatic spinal cord injury, where pharmacological blockade of Sur1 (glibenclamide, repaglinide) or of Trpm4 (flufenamic acid, riluzole), gene suppression (antisense oligodeoxynucleotide against $A b c c 8$ or Trpm4), and gene silencing ( $A b c c 8$ -/- or Trpm4-/-), all were shown to result in exactly the same phenotype-educed microvascular dysfunction and capillary fragmentation [94]. Similarly, in a murine model of experimental autoimmune encephalomyelitis, silencing of Abcc8 or of Trpm 4 results in the same phenotype, with reduced neuroinflammation and preservation of white matter $[36,95]$. Our present findings extend these previous observations, showing that in TLR4-mediated neuroinflammation, silencing $A b c c 8$ or Trpm4 results in the same phenotype-preferential activation of CaMKII over $\mathrm{CN}$ / NFATc1 and reduced induction of Nos2/NOS2.

Our findings indicate that Trpm4 is the major molecular partner of Sur1 following TLR4 activation in microglia and that the beneficial effects of glibenclamide in the setting of TLR4-induced neuroinflammation may be due, in part, to augmented CaMKII signaling in microglia. Blockade of Sur1-Trpm4 by glibenclamide previously was shown to be protective in models of ischemic and traumatic CNS injury, where the activity of Sur1Trpm4 in neurons, astrocytes, and endothelial cells can result in excess $\mathrm{Na}^{+}$influx leading to catastrophic cell swelling [26]. In microglia, however, the activity of Sur1Trpm4 is deleterious for a different reason-namely, it aids in the dynamic regulation of $\left[\mathrm{Ca}^{2+}\right]_{\mathrm{i}}$ that is required for a sustained neuroinflammatory response.

\section{Conclusions}

Sur1-Trpm4 channels constitute a novel mechanism by which TLR4-activated microglia regulate pro-inflammatory, $\mathrm{Ca}^{2+}$-sensitive gene expression, including Nos2/NOS2. Glibenclamide blockade of Sur1-Trpm4 is promising for the future treatment of CNS diseases involving neuroinflammation and nitrosative/oxidative stress.

\section{Abbreviations}

$\left[\mathrm{Ca}^{2+}\right]_{\mathrm{i}}$, intracellular concentration of calcium; aCSF, artificial cerebrospinal fluid; ANOVA, analysis of variance; BAPTA-AM, 1,2-bis(2-Aminophenoxy)ethane- $N, N, N^{\prime}, N$ '-tetraacetic acid acetoxymethyl ester; CaMKII, $\mathrm{Ca}^{2+}$ / calmodulin protein kinase II; Cd11b, cluster of differentiation molecule 11b; CD68/ED1, cluster of differentiation molecule 68; CHAPS, 3-[(3-cholamidopropyl)dimethylammonio]-1-propanesulfonate; ChIP, chromatin immunoprecipitation; $\mathrm{CN}$, calcineurin; CNS, central nervous system; DAMP, danger-associated-molecular pattern; DAPI, 4',6diamidino-2-phenylindole; DIG, digoxigenin; DMEM, 
Dulbecco's modified Eagle's medium; DMSO, dimethylsulfoxide; FBS, fetal bovine serum; Gapdh, glyceraldehyde 3phosphate dehydrogenase; Gfap, glial fibrillary acidic protein; HBSS, Hank's balanced salt solution; HDAC1, histone deacetylase 1; Ibal, ionized $\mathrm{Ca}^{2+}$-binding adapter molecule 1; IMDM, Iscove's modified Dulbecco's medium; IP, immunoprecipitation; ISH, in situ hybridization; $\mathrm{K}_{\mathrm{ATB}}$ ATP-sensitive potassium channel; LDH, lactate dehydrogenase; LPS, lipopolysaccharide; NFAT, nuclear factor of activated T-cells; NO, nitric oxide; NOS2, inducible nitric oxide synthase; NS, normal saline; PPI, protease and phosphatase inhibitor cocktail; qPCR, quantitative real-time polymerase chain reaction; RIPA, radioimmunoprecipitation assay; ROCE, receptor-operated $\mathrm{Ca}^{2+}$ entry; ROI, region of interest; SDS-PAGE, sodium dodecyl sulfate polyacrylamide gel electrophoresis; SIP, standard isotonic Percoll; SOCE, store-operated $\mathrm{Ca}^{2+}$ entry; Sur1, sulfonylurea receptor 1; TLR4, Toll-like receptor 4; Trpm4, transient receptor potential melastatin 4; VOCE, voltage-operated $\mathrm{Ca}^{2+}$ entry; WT, wild type

\section{Acknowledgements}

We extend our warmest thanks to Dr. Alexander Ivanov, Neurosurgery Department, University of Maryland School of Medicine, for his excellent technical support. We are indebted to Dr. Jing Yin and Ms. Li Tang, University of Maryland School of Medicine Biopolymer-Genomics Core Facility, for their early guidance in preparing high-quality RNA samples. DBK extends his deepest gratitude to members of his doctoral thesis committee, Drs. Stefanie Vogel, David Loane, Ronna Herztano, Leonardo Tonelli, Volodymyr Gerzanich, and J. Marc Simard, whose guidance was central to the completion of this work

\section{Funding}

This work was supported by grants to JMS from the National Institute of Neurological Disorders and Stroke (NINDS) (NS060801; NS061808), the National Heart, Lung and Blood Institute (HL082517) and the U.S. Department of Veterans Affairs (1BX002889), to VG from NINDS (NS061934; NS072501), and to MF by the Deutsche Forschungsgemeinschaft (FOR 2289: FR1638/3-1).

\section{Availability of data and materials}

The authors are willing to make readily reproducible materials, including all relevant raw data, freely available to any scientist wishing to use them. Unfortunately, our institution does not provide a secure mechanism for anonymous sharing. Please email the corresponding authors.

\section{Authors' contributions \\ DBK conceived of and performed all experiments except patch clamp and prepared drafts of the manuscript. VG analyzed the experimental data, prepared the figures, and made critical contributions to the study design and manuscript preparation. JKK assisted in performing the experiments. SKW aided with the ChIP experiments. RV and MF developed and supplied the Trpm4-/- mouse. BN provided guidance on the TRPM4 experiments. JB developed and supplied the Abcc8-/- mouse. JMS conceived of the study and wrote the final manuscript. All authors read and approved the final manuscript.}

\section{Competing interests}

Dr. Simard holds a US patent $(7,285,574)$, a novel non-selective cation channel in neural cells and methods for treating brain swelling. Dr. Simard is a member of the scientific advisory board and holds shares in Remedy Pharmaceuticals. No support, direct or indirect, was provided to Dr. Simard, or for this project, by Remedy Pharmaceuticals. All other authors report no conflicts.
Consent for publication

Not applicable.

\section{Ethics approval and consent to participate}

We certify that all applicable institutional and governmental regulations concerning the ethical use of animals were followed during the course of this research. Animal experiments were performed under a protocol approved by the Institutional Animal Care and Use Committee (IACUC) of the University of Maryland, Baltimore, and in accordance with the relevant guidelines and regulations as stipulated in the United States National Institutes of Health Guide for the Care and Use of Laboratory Animals. All efforts were made to minimize the number of animals used and their suffering.

\section{Author details}

${ }^{1}$ Department of Neurosurgery, University of Maryland School of Medicine, 22 S. Greene St., Suite S12D, Baltimore, MD 21201-1595, USA. ${ }^{2}$ Department of Pathology, University of Maryland School of Medicine, Baltimore, MD, USA. ${ }^{3}$ Department of Physiology, University of Maryland School of Medicine, Baltimore, MD, USA. ${ }^{4}$ Department Cell Molecular Medicine, Laboratory lon Channel Research, Campus Gasthuisberg, Herestraat 49-Bus 802, Leuven 3000, Belgium. ${ }^{5}$ Pharmakologisches Institut, Universität Heidelberg, Im Neuenheimer Feld 366, Heidelberg 69120, Germany. ${ }^{6}$ Pacific Northwest Diabetes Research Institute, 720 Broadway, Seattle, WA 98122, USA.

${ }^{7}$ Neurosurgery Research Laboratories, $10 \mathrm{~S}$. Pine St, Baltimore, MD 21201-1595, USA.

Received: 19 February 2016 Accepted: 24 May 2016

Published online: 01 June 2016

\section{References}

1. Fang H, Wang PF, Zhou Y, Wang YC, Yang QW. Toll-like receptor 4 signaling in intracerebral hemorrhage-induced inflammation and injury. J Neuroinflammation. 2013:10:27.

2. Trotta T, Porro C, Calvello R, Panaro MA. Biological role of Toll-like receptor-4 in the brain. J Neuroimmunol. 2014;268:1-12.

3. Laird MD, Shields JS, Sukumari-Ramesh S, Kimbler DE, Fessler RD, Shakir B, et al. High mobility group box protein-1 promotes cerebral edema after traumatic brain injury via activation of toll-like receptor 4. Glia. 2014;62:26-38.

4. Famakin BM, Mou Y, Johnson $K$, Spatz M, Hallenbeck J. A new role for downstream Toll-like receptor signaling in mediating immediate early gene expression during focal cerebral ischemia. J Cereb Blood Flow Metab. 2014; 34:258-67.

5. Erridge C. Endogenous ligands of TLR2 and TLR4: agonists or assistants? J Leukoc Biol. 2010;87:989-99.

6. Kurland DB, Gerzanich V, Simard JM. DAMPs converging on Toll-like receptor 4 in hemorrhagic stroke, a MiniReview. Curr Neurobio. 2015;6:3-4

7. Lehnardt S, Massillon L, Follett P, Jensen FE, Ratan R, Rosenberg PA, et al. Activation of innate immunity in the CNS triggers neurodegeneration through a Toll-like receptor 4-dependent pathway. Proc Natl Acad Sci U S A. 2003;100:8514-9.

8. Yuste JE, Tarragon E, Campuzano CM, Ros-Bernal F. Implications of glial nitric oxide in neurodegenerative diseases. Front Cell Neurosci. 2015:9:322.

9. Ritzel RM, Patel AR, Grenier JM, Crapser J, Verma R, Jellison ER, et al. Functional differences between microglia and monocytes after ischemic stroke. J Neuroinflammation. 2015;12:106

10. Schneider UC, Davids AM, Brandenburg S, Muller A, Elke A, Magrini S, et al. Microglia inflict delayed brain injury after subarachnoid hemorrhage. Acta Neuropathol. 2015;130:215-31.

11. van Dijk BJ, Vergouwen MD, Kelfkens MM, Rinkel GJ, Hol EM. Glial cell response after aneurysmal subarachnoid hemorrhage_functional consequences and clinical implications. Biochim Biophys Acta. 2016;1862(3): 492-505.

12. Bechade $\mathrm{C}$, Colasse $\mathrm{S}$, Diana MA, Rouault M, Bessis A. NOS2 expression is restricted to neurons in the healthy brain but is triggered in microglia upon inflammation. Glia. 2014;62:956-63.

13. Kumar A, Chen SH, Kadiiska MB, Hong JS, Zielonka J, Kalyanaraman B, et al. Inducible nitric oxide synthase is key to peroxynitrite-mediated, LPS-induced protein radical formation in murine microglial BV2 cells. Free Radic Biol Med. 2014;73:51-9.

14. Obasanjo-Blackshire K, Mesquita R, Jabr RI, Molkentin JD, Hart SL, Marber MS, et al. Calcineurin regulates NFAT-dependent iNOS expression and 
protection of cardiomyocytes: co-operation with Src tyrosine kinase. Cardiovasc Res. 2006;71:672-83.

15. Ranjan R, Deng J, Chung S, Lee YG, Park GY, Xiao L, et al. The transcription factor nuclear factor of activated T cells $\mathrm{c} 3$ modulates the function of macrophages in sepsis. J Innate Immun. 2014;6:754-64.

16. Jones RJ, Jourd'heuil D, Salerno JC, Smith SM, Singer HA. iNOS regulation by calcium/calmodulin-dependent protein kinase II in vascular smooth muscle. Am J Physiol Heart Circ Physiol. 2007;292:H2634-42.

17. Kreusser MM, Lehmann LH, Keranov S, Hoting MO, Oehl U, Kohlhaas M, et al. Cardiac CaM Kinase II genes delta and gamma contribute to adverse remodeling but redundantly inhibit calcineurin-induced myocardial hypertrophy. Circulation. 2014;130:1262-73.

18. Farber $\mathrm{K}$, Kettenmann $\mathrm{H}$. Functional role of calcium signals for microglial function. Glia. 2006;54:656-65.

19. Kettenmann H, Hanisch UK, Noda M, Verkhratsky A. Physiology of microglia. Physiol Rev. 2011;91:461-553.

20. Sharma P, Ping L. Calcium ion influx in microglial cells: physiological and therapeutic significance. J Neurosci Res. 2014;92:409-23.

21. Moller T. Calcium signaling in microglial cells. Glia. 2002;40:184-94.

22. Espinosa-Parrilla JF, Martinez-Moreno M, Gasull X, Mahy N, Rodriguez MJ. The L-type voltage-gated calcium channel modulates microglial proinflammatory activity. Mol Cell Neurosci. 2015;64:104-15.

23. Verkhratsky A, Parpura V. Store-operated calcium entry in neuroglia. Neurosci Bull. 2014;30:125-33.

24. Michaelis M, Nieswandt B, Stegner D, Eilers J, Kraft R. STIM1, STIM2, and Orai1 regulate store-operated calcium entry and purinergic activation of microglia. Glia. 2015;63:652-63.

25. Ohana L, Newell EW, Stanley EF, Schlichter LC. The Ca2+ release-activated Ca2+ current (I(CRAC)) mediates store-operated $\mathrm{Ca} 2+$ entry in rat microglia. Channels (Austin). 2009:3:129-39.

26. Simard JM, Woo SK, Schwartzbauer GT, Gerzanich V. Sulfonylurea receptor 1 in central nervous system injury: a focused review. J Cereb Blood Flow Metab. 2012;32:1699-717.

27. Yang SN, Shi Y, Yang G, Li Y, Yu J, Berggren PO. lonic mechanisms in pancreatic beta cell signaling. Cell Mol Life Sci. 2014;71:4149-77.

28. Launay P, Cheng H, Srivatsan S, Penner R, Fleig A, Kinet JP. TRPM4 regulates calcium oscillations after T cell activation. Science. 2004;306:1374-7.

29. Vennekens R, Olausson J, Meissner M, Bloch W, Mathar I, Philipp SE, et al. Increased lgE-dependent mast cell activation and anaphylactic responses in mice lacking the calcium-activated nonselective cation channel TRPM4. Nat Immunol. 2007;8:312-20.

30. Park JY, Hwang EM, Yarishkin O, Seo JH, Kim E, Yoo J, et al. TRPM4b channel suppresses store-operated $\mathrm{Ca} 2+$ entry by a novel protein-protein interaction with the TRPC3 channel. Biochem Biophys Res Commun. 2008;368:677-83.

31. Freichel M, Almering J, Tsvilovskyy V. The role of TRP proteins in mast cells. Front Immunol. 2012;3:150.

32. Ortega FJ, Gimeno-Bayon J, Espinosa-Parrilla JF, Carrasco JL, Batlle M, Pugliese M, et al. ATP-dependent potassium channel blockade strengthens microglial neuroprotection after hypoxia-ischemia in rats. Exp Neurol. 2012; 235:282-96.

33. Ortega FJ, Jolkkonen J, Mahy N, Rodriguez MJ. Glibenclamide enhances neurogenesis and improves long-term functional recovery after transient focal cerebral ischemia. J Cereb Blood Flow Metab. 2013;33:356-64.

34. Ortega FJ, Vukovic J, Rodriguez MJ, Bartlett PF. Blockade of microglial KATPchannel abrogates suppression of inflammatory-mediated inhibition of neural precursor cells. Glia. 2014;62:247-58.

35. Redondo-Castro E, Hernandez J, Mahy N, Navarro X. Phagocytic microglial phenotype induced by glibenclamide improves functional recovery but worsens hyperalgesia after spinal cord injury in adult rats. Eur J Neurosci. 2013;38:3786-98

36. Makar TK, Gerzanich V, Nimmagadda VK, Jain R, Lam K, Mubariz F, et al. Silencing of Abcc8 or inhibition of newly upregulated Sur1-Trpm4 reduce inflammation and disease progression in experimental autoimmune encephalomyelitis. J Neuroinflammation. 2015;12:210.

37. Simard JM, Geng Z, Woo SK, Ivanova S, Tosun C, Melnichenko L, et al. Glibenclamide reduces inflammation, vasogenic edema, and caspase-3 activation after subarachnoid hemorrhage. J Cereb Blood Flow Metab. 2009;29:317-30.

38. Tosun C, Kurland DB, Mehta R, Castellani RJ, de Jong JL, Kwon MS, et al. Inhibition of the Sur1-Trpm4 channel reduces neuroinflammation and cognitive impairment in subarachnoid hemorrhage. Stroke. 2013;44:3522-8.
39. Gerzanich V, Woo SK, Vennekens R, Tsymbalyuk O, Ivanova S, Ivanov A, et al. De novo expression of Trpm4 initiates secondary hemorrhage in spinal cord injury. Nat Med. 2009;15:185-91.

40. Seghers V, Nakazaki M, DeMayo F, Aguilar-Bryan L, Bryan J. Sur1 knockout mice. A model for K(ATP) channel-independent regulation of insulin secretion. J Biol Chem. 2000;275:9270-7.

41. Woo SK, Kwon MS, Ivanov A, Gerzanich V, Simard JM. The sulfonylurea receptor 1 (Sur1)-transient receptor potential melastatin 4 (Trpm4) channel. J Biol Chem. 2013;288:3655-67.

42. Lee JK, Tansey MG. Microglia isolation from adult mouse brain. Methods Mol Biol. 2013;1041:17-23.

43. Bustin SA, Benes V, Garson JA, Hellemans J, Huggett J, Kubista M, et al. The MIQE guidelines: minimum information for publication of quantitative realtime PCR experiments. Clin Chem. 2009;55:611-22.

44. Chen M, Simard JM. Cell swelling and a nonselective cation channel regulated by internal $\mathrm{Ca} 2+$ and ATP in native reactive astrocytes from adult rat brain. J Neurosci. 2001;21:6512-21.

45. Chen M, Dong Y, Simard JM. Functional coupling between sulfonylurea receptor type 1 and a nonselective cation channel in reactive astrocytes from adult rat brain. J Neurosci. 2003;23:8568-77.

46. Zhang Z, Okawa H, Wang Y, Liman ER. Phosphatidylinositol 4,5bisphosphate rescues TRPM4 channels from desensitization. J Biol Chem. 2005:280:39185-92.

47. Nilius B, Mahieu F, Prenen J, Janssens A, Owsianik G, Vennekens R, et al. The Ca2+-activated cation channel TRPM4 is regulated by phosphatidylinositol 4,5-biphosphate. EMBO J. 2006;25:467-78.

48. Olsen KM, Kearns GL, Kemp SF. Glyburide protein binding and the effect of albumin glycation in children, young adults, and older adults with diabetes. J Clin Pharmacol. 1995;35:739-45.

49. Simard JM, Woo SK, Tsymbalyuk N, Voloshyn O, Yurovsky V, Ivanova S, et al. Glibenclamide-10-h treatment window in a clinically relevant model of stroke. Transl Stroke Res. 2012;3:286-95.

50. Liu F, Zhou R, Yan H, Yin H, Wu X, Tan Y, et al. Metabotropic glutamate receptor 5 modulates calcium oscillation and innate immune response induced by lipopolysaccharide in microglial cell. Neuroscience. 2014;281C:24-34.

51. Noworyta-Sokolowska K, Gorska A, Golembiowska K. LPS-induced oxidative stress and inflammatory reaction in the rat striatum. Pharmacol Rep. 2013; 65:863-9.

52. Hickman SE, Kingery ND, Ohsumi TK, Borowsky ML, Wang LC, Means TK, et al. The microglial sensome revealed by direct RNA sequencing. Nat Neurosci. 2013;16:1896-905.

53. Vilhardt F. Microglia: phagocyte and glia cell. Int J Biochem Cell Biol. 2005;37:17-21.

54. Mehta RI, Ivanova S, Tosun C, Castellani RJ, Gerzanich V, Simard JM. Sulfonylurea receptor 1 expression in human cerebral infarcts. J Neuropathol Exp Neurol. 2013;72:871-83.

55. Mehta RI, Tosun C, Ivanova S, Tsymbalyuk N, Famakin BM, Kwon MS, et al. Sur1-Trpm4 cation channel expression in human cerebral infarcts. J Neuropathol Exp Neurol. 2015;74:835-49.

56. Blodow A, Begandt D, Bader A, Becker A, Burghard A, Kuhne D, Kral A, Ngezahayo A. ATP-sensitive K channels (Kir6.1/SUR1) regulate gap junctional coupling in cochlear-supporting cells. Pflugers Arch. 2016;1-8. http://www. ncbi.nlm.nih.gov/pubmed/27030354?dopt=Citation.

57. Karschin C, Ecke C, Ashcroft FM, Karschin A. Overlapping distribution of K(ATP) channel-forming Kir6.2 subunit and the sulfonylurea receptor SUR1 in rodent brain. FEBS Lett. 1997:401:59-64.

58. Beck A, Penner R, Fleig A. Lipopolysaccharide-induced down-regulation of Ca2 + release-activated Ca2+ currents (I CRAC) but not Ca2+-activated TRPM4-like currents (I CAN) in cultured mouse microglial cells. J Physiol. 2008;586:427-39.

59. Livermore S, Piskuric NA, Buttigieg J, Zhang M, Nurse CA. Low glucose sensitivity and polymodal chemosensing in neonatal rat adrenomedullary chromaffin cells. Am J Physiol Cell Physiol. 2011;301:C1104-15.

60. Stansley B, Post J, Hensley K. A comparative review of cell culture systems for the study of microglial biology in Alzheimer's disease. J Neuroinflammation. 2012;9:115

61. Hoffmann A, Kann O, Ohlemeyer C, Hanisch UK, Kettenmann H. Elevation of basal intracellular calcium as a central element in the activation of brain macrophages (microglia): suppression of receptor-evoked calcium signaling and control of release function. J Neurosci. 2003;23:4410-9.

62. Stebbing MJ, Cottee JM, Rana I. The role of ion channels in microglial activation and proliferation-a complex interplay between ligand-gated ion channels, $\mathrm{K}(+)$ channels, and intracellular $\mathrm{Ca}(2$.$) . Front Immunol. 2015;6:497.$ 
63. Weber KS, Hildner K, Murphy KM, Allen PM. Trpm4 differentially regulates Th1 and Th2 function by altering calcium signaling and NFAT localization. J Immunol. 2010;185:2836-46.

64. Matzner N, Zemtsova IM, Nguyen TX, Duszenko M, Shumilina E, Lang F. Ion channels modulating mouse dendritic cell functions. J Immunol. 2008;181:6803-9.

65. Li JH, Zhao ST, Wu CY, Cao X, Peng MR, Li SJ, et al. Store-operated Ca2+ channels blockers inhibit lipopolysaccharide induced astrocyte activation. Neurochem Res. 2013;38:2216-26.

66. Johnston L, Sergeant GP, Hollywood MA, Thornbury KD, McHale NG. Calcium oscillations in interstitial cells of the rabbit urethra. J Physiol. 2005:565:449-61.

67. Ariano P, Dalmazzo S, Owsianik G, Nilius B, Lovisolo D. TRPC channels are involved in calcium-dependent migration and proliferation in immortalized GnRH neurons. Cell Calcium. 2011:49:387-94.

68. Guinamard R, Hof T, Del Negro CA. The TRPM4 channel inhibitor 9phenanthrol. Br J Pharmacol. 2014;171:1600-13.

69. Mathar I, Kecskes M, Van der Mieren G, Jacobs G, Camacho Londono JE, Uhl $S$, et al. Increased beta-adrenergic inotropy in ventricular myocardium from Trpm4-/- mice. Circ Res. 2014;114:283-94.

70. Vennekens R, Nilius B. Insights into TRPM4 function, regulation and physiological role. Handb Exp Pharmacol. 2007;179:269-285.

71. Ferrari D, Stroh C, Schulze-Osthoff K. P2X7/P2Z purinoreceptor-mediated activation of transcription factor NFAT in microglial cells. J Biol Chem. 1999; 274:13205-10

72. Nagamoto-Combs K, Combs CK. Microglial phenotype is regulated by activity of the transcription factor, NFAT (nuclear factor of activated T cells). J Neurosci. 2010:30:9641-6.

73. Ferrari D, Stroh C, Wesselborg S, Di Virgilio F, Schulze-Osthoff K. Extracellular ATP activates transcription factor NFAT in mouse microglial cells. Drug Dev Res. 2001;52:213-9.

74. Hogan PG, Chen L, Nardone J, Rao A. Transcriptional regulation by calcium, calcineurin, and NFAT. Genes Dev. 2003;17:2205-32.

75. Wang C, Li JF, Zhao L, Liu J, Wan J, Wang YX, et al. Inhibition of SOC/Ca2 +/NFAT pathway is involved in the anti-proliferative effect of sildenafil on pulmonary artery smooth muscle cells. Respir Res. 2009;10:123.

76. MacDonnell SM, Weisser-Thomas J, Kubo H, Hanscome M, Liu Q, Jaleel N, et al. CaMKII negatively regulates calcineurin-NFAT signaling in cardiac myocytes. Circ Res. 2009;105:316-25.

77. Erickson JR. Mechanisms of CaMKII activation in the heart. Front Pharmacol. 2014;5:59.

78. Elloumi HZ, Maharshak N, Rao KN, Kobayashi T, Ryu HS, Muhlbauer M, et al. A cell permeable peptide inhibitor of NFAT inhibits macrophage cytokine expression and ameliorates experimental colitis. PLoS One. 2012;7, e34172.

79. MacKenzie EL, Tsuji Y. Elevated intracellular calcium increases ferritin $\mathrm{H}$ expression through an NFAT-independent post-transcriptional mechanism involving mRNA stabilization. Biochem J. 2008:411:107-13.

80. Serfling E, Avots A, Klein-Hessling S, Rudolf R, Vaeth M, Berberich-Siebelt F. NFATc1/alphaA: the other face of NFAT factors in lymphocytes. Cell Commun Signal. 2012;10:16.

81. Barbado M, Fablet K, Ronjat M, De WM. Gene regulation by voltagedependent calcium channels. Biochim Biophys Acta. 2009;1793:1096-104.

82. Selvaraj S, Sun Y, Singh BB. TRPC channels and their implication in neurological diseases. CNS Neurol Disord Drug Targets. 2010;9:94-104.

83. Butovsky O, Jedrychowski MP, Moore CS, Cialic R, Lanser AJ, Gabriely G, et al. Identification of a unique TGF-beta-dependent molecular and functional signature in microglia. Nat Neurosci. 2014;17:131-43.

84. Virgili N, Espinosa-Parrilla JF, Mancera P, Pasten-Zamorano A, Gimeno-Bayon J, Rodriguez MJ, et al. Oral administration of the KATP channel opener diazoxide ameliorates disease progression in a murine model of multiple sclerosis. J Neuroinflammation. 2011;8:149.

85. Kingwell K. Neurodegenerative disease: microglia in early disease stages. Nat Rev Neurol. 2012;8:475.

86. Perry VH, Nicoll JA, Holmes C. Microglia in neurodegenerative disease. Nat Rev Neurol. 2010;6:193-201.

87. Eder C. Regulation of microglial behavior by ion channel activity. J Neurosci Res. 2005;81:314-21.

88. Dolmetsch RE, Lewis RS, Goodnow CC, Healy Jl. Differential activation of transcription factors induced by $\mathrm{Ca} 2+$ response amplitude and duration. Nature. 1997:386:855-8.

89. Clapham DE. Calcium signaling. Cell. 2007;131:1047-58.
90. Tomida T, Hirose K, Takizawa A, Shibasaki F, lino M. NFAT functions as a working memory of $\mathrm{Ca} 2+$ signals in decoding Ca2+ oscillation. EMBO J. 2003;22:3825-32.

91. Ferreira $\mathrm{R}$, Wong $\mathrm{R}$, Schlichter LC. KCa3.1/IK1 channel regulation by CGMPdependent protein kinase (PKG) via reactive oxygen species and CaMKII in microglia: an immune modulating feedback system? Front Immunol. 2015;6:153.

92. Liu X, Wu JY, Zhou F, Sun XL, Yao HH, Yang Y, et al. The regulation of rotenone-induced inflammatory factor production by ATP-sensitive potassium channel expressed in BV-2 cells. Neurosci Lett. 2006;394:131-5.

93. Rodriguez MJ, Martinez-Moreno M, Ortega FJ, Mahy N. Targeting microglial K(ATP) channels to treat neurodegenerative diseases: a mitochondrial issue. Oxid Med Cell Longev. 2013;2013:194546.

94. Simard JM, Woo SK, Aarabi B, Gerzanich V. The Sur1-Trpm4 channel in spina cord injury. J Spine. 2013;(4):002. http://www.ncbi.nlm.nih.gov/pubmed/ 24834370?dopt=Citation

95. Schattling B, Steinbach K, Thies E, Kruse M, Menigoz A, Ufer F, et al. TRPM4 cation channel mediates axonal and neuronal degeneration in experimental autoimmune encephalomyelitis and multiple sclerosis. Nat Med. 2012;18:1805-11.

\section{Submit your next manuscript to BioMed Central and we will help you at every step:}

- We accept pre-submission inquiries

- Our selector tool helps you to find the most relevant journal

- We provide round the clock customer support

- Convenient online submission

- Thorough peer review

- Inclusion in PubMed and all major indexing services

- Maximum visibility for your research

Submit your manuscript at www.biomedcentral.com/submit

) Biomed Central 